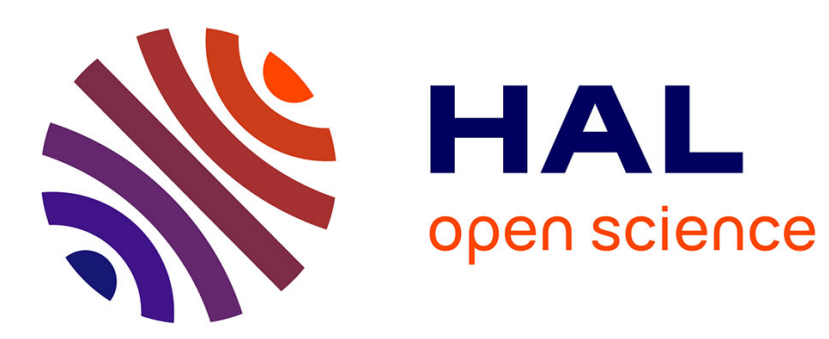

\title{
Tracking fluid pressure buildup from focal mechanisms during the 2003-2004 Ubaye seismic swarm, France,
}

H. Leclère, G. Daniel, O. Fabbri, F. Cappa, F. Thouvenot

\section{To cite this version:}

H. Leclère, G. Daniel, O. Fabbri, F. Cappa, F. Thouvenot. Tracking fluid pressure buildup from focal mechanisms during the 2003-2004 Ubaye seismic swarm, France,. Journal of Geophysical Research: Solid Earth, 2013, 118 (8), pp.4461-4476. 10.1002/jgrb.50297 . hal-00876540

\section{HAL Id: hal-00876540 \\ https://hal.science/hal-00876540}

Submitted on 20 May 2021

HAL is a multi-disciplinary open access archive for the deposit and dissemination of scientific research documents, whether they are published or not. The documents may come from teaching and research institutions in France or abroad, or from public or private research centers.
L'archive ouverte pluridisciplinaire HAL, est destinée au dépôt et à la diffusion de documents scientifiques de niveau recherche, publiés ou non, émanant des établissements d'enseignement et de recherche français ou étrangers, des laboratoires publics ou privés. 


\title{
Tracking fluid pressure buildup from focal mechanisms during the 2003-2004 Ubaye seismic swarm, France
}

\author{
Henri Leclère, ${ }^{1,2}$ Guillaume Daniel,${ }^{3}$ Olivier Fabbri, ${ }^{1}$ Frédéric Cappa, ${ }^{4}$ \\ and François Thouvenot ${ }^{5}$ \\ Received 13 March 2013; revised 4 July 2013; accepted 16 July 2013; published 16 August 2013.
}

[1] Recent studies have shown that the Ubaye seismic swarm that occurred in the French southwestern Alps in 2003-2004 was triggered by fluid overpressures. This contribution provides additional constraints on the temporal and spatial changes in fluid overpressure during this swarm. The orientations of the double-couple nodal planes of an extended set of 74 focal solutions, spanning the whole 2003-2004 episode, are compared with the regional stress field. Based on a Mohr-Coulomb analysis, these comparisons provide estimates of fluid pressures along seismic fault planes. We show that the fluid overpressures required to reactivate the cohesionless fault planes vary through time, with values close to $35 \mathrm{MPa}$ at the inception of the swarm. Overpressures then increase up to $55 \mathrm{MPa}$ during the burst of seismic activity and lastly decrease down to $20 \mathrm{MPa}$ at the end of the crisis. We also show that the fluid overpressures are developed as patches along two parallel faults bordering a releasing bend structure characterized by low to null overpressure. The development of moderate fluid overpressure at the swarm inception enables the reactivation of normal, transtensional, and strike-slip faults while the development of larger fluid overpressures during the burst of seismic activity progressively enables the reactivation of further misoriented normal, transtensional, and transpressional faults. In order to reconcile the spatial and temporal evolution of the fluid overpressures and the seismic activity, we propose that creep compaction could be the process allowing the successive development of fluid overpressure and the migration of seismicity.

Citation: Leclère, H., G. Daniel, O. Fabbri, F. Cappa, and F. Thouvenot (2013), Tracking fluid pressure buildup from focal mechanisms during the 2003-2004 Ubaye seismic swarm, France, J. Geophys. Res. Solid Earth, 118, 4461-4476, doi:10.1002/jgrb.50297.

\section{Introduction}

[2] Seismic swarms are characterized by short and intense microseismic activity. This atypical character consists in alternations of bursts of seismic activity and periods of low seismic rate. Although seismic swarms do not represent a significant seismic risk, as they are most often made up of low-magnitude events, they can, however, precede large earthquakes [Bouchon et al., 2011]. The Ubaye area, southeastern France, has been the location of several moderate earthquakes, from a $M_{L} 5.5$ event in April 1959 to the most recent $M_{L} 4.3$ in February 2012. Consequently, the close monitoring of such

\footnotetext{
${ }^{1}$ UMR CNRS 6249, Université de Franche-Comté, Besançon, France.

${ }^{2}$ Now at Rock Deformation Laboratory, Department of Earth and Ocean Sciences, University of Liverpool, Liverpool, UK

${ }^{3}$ Magnitude, Sainte-Tulle, France.

${ }^{4}$ Geoazur (UMR 6526), Université de Nice Sophia-Antipolis, Observatoire de la Côte d'Azur, Sophia-Antipolis, France.

${ }^{5}$ ISTerre (Institut des Sciences de la Terre) Observatoire, Université Joseph Fourier Grenoble, CNRS, BP 53, Grenoble, France.

Corresponding author: H. Leclère, Rock Deformation Laboratory, Department of Earth and Ocean Sciences, University of Liverpool, Liverpool L69 3GP, UK. (henri.leclere@liv.ac.uk)

(C2013. American Geophysical Union. All Rights Reserved. 2169-9313/13/10.1002/jgrb.50297
}

episodic crises enables us to gain knowledge on the physical processes controlling the emergence of seismic activity.

[3] Seismic swarms have been described in volcanic regions where their occurrence is related to magma intrusion and/or to fluid degassing, inducing pore pressure increase and fault reactivation [e.g., Nur, 1974; Hill, 1977; Vidale et al., 2006; Hensch et al., 2008; Yukutake et al., 2011]. Besides, their occurrence has also been discussed in nonvolcanic areas where mantle volatiles, or meteoric water, can be the common trigger for seismic activity, for fluid overpressure, or for fluid migration [Costain et al., 1987; Bella et al., 1998; Weise et al., 2001; Hainzl et al., 2006; Bollinger et al., 2007, Rigo et al., 2008, Bräuer et al., 2009, Got et al., 2011].

[4] These studies share the common belief that fluid overpressure plays a key role in seismic triggering and fault reactivation [see also Nur and Booker, 1972; Hickman et al., 1995; Miller et al., 2004; Hainzl et al., 2006; Cappa et al., 2009]. The mechanical effect of fluid overpressure on faults is to reduce the normal stress acting on the fault and hence to promote its reactivation. However, direct observations or measurements of fluid overpressures during swarm episodes are not systematically available, and methodological alternatives are needed to clarify the relationships between fluid pressure excess and swarm activity. For example, computational methods based on the seismicity rates modeling [Hainzl and Ogata, 2005; Daniel et al., 2011], on hydromechanical 


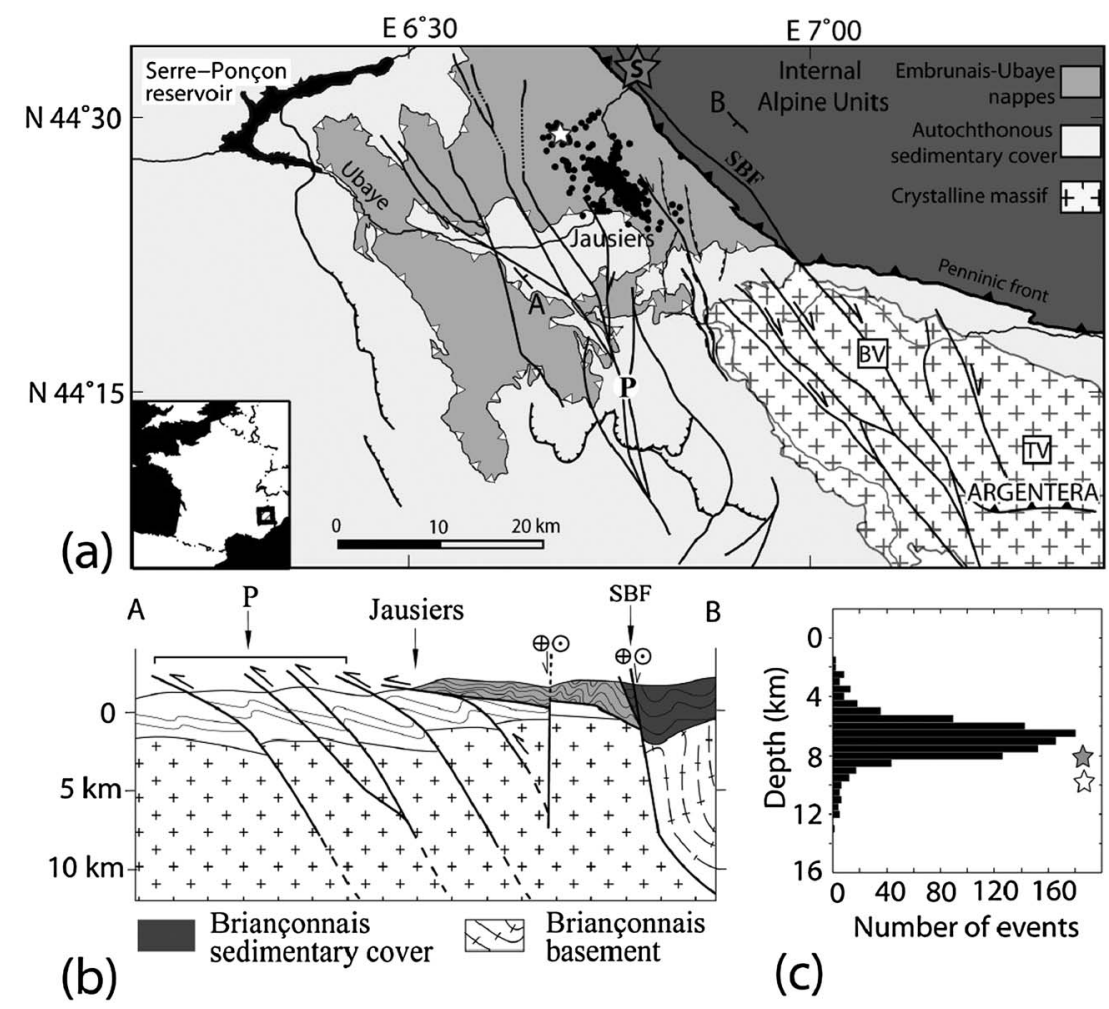

Figure 1. Geological setting of the study area. (a) Simplified geological map. SBF: Serenne-Bersezio fault; P: Parpaillon faults; BV: Bagni di Vinadio thermal springs; TV: Terme di Valdieri thermal springs. The gray star indicates the location of the epicenter of the $1959 M_{L} 5.3$ Saint-Paul-sur-Ubaye earthquake [Nicolas et al., 1998]. The white star indicates the location of the epicenter of the $2012 M_{L} 4.3$ earthquake. For simplicity, Briançonnais thrust sheets [Kerckhove et al., 1980; Fry, 1989] are omitted. Black dots show the 974 relocated epicenters of the 2003-2004 Ubaye swarm. (b) Cross section A-B showing the relationships between the crystalline basement, the autochthonous sedimentary cover, and the Embrunais-Ubaye nappes. (c) Depth-frequency of the 974 relocated events of the 2003-2004 seismic swarm [after Daniel et al. 2011]. Depths are taken from a mean surface elevation fixed at $1500 \mathrm{~m}$, elevation of the Jausiers village. The gray star indicates the hypocentral depth of the Saint-Paul-sur-Ubaye earthquake, and the white star indicates the hypocentral depth of the $2012 M_{L} 4.3$ earthquake.

modeling [Miller et al., 2004; Cappa et al., 2009], on geodetic data [Lohman and McGuire, 2007], or on Mohr-Coulomb theory [Sibson, 1985, 2000; Cox, 2010] have been proposed to determine the state of stress on faults and the fluid pressures required for fault reactivation.

[5] In the Ubaye area, several studies have proposed that fluid flow at depth could be a possible triggering mechanism for the 2003-2004 seismic sequence [Jenatton et al., 2007; Daniel et al., 2011; Leclère et al., 2012]. These propositions are based on the observation of a nonstationary state background seismicity rate [Daniel et al., 2011] and on inappropriate fault orientations with respect to the orientations of the principal axes of the regional stress field [Leclère et al., 2012].

[6] Here we attempt to go beyond the study of Leclère et al. [2012] by providing additional constraints on the temporal and spatial changes in fluid overpressure. For this purpose, we use an extended set of 74 focal solutions for the Ubaye swarm, spanning the whole 2003-2004 episode. Our approach is based on the analysis of double-couple nodal plane orientations within the ambient regional stress field. If compared to the method used by Terakawa et al. [2010], this study represents an improvement, as it takes into account the existing competition between reactivation and fracture creation processes on target fault planes. To do so, we test whether the fluid overpressure required to reactivate fault planes does or does not exceed the fluid overpressure required to create new optimally oriented fractures. We then reconstruct the pore pressure buildup history within the Ubaye swarm seismogenic volume from a set of fluid overpressure estimates obtained from focal mechanisms.

[7] Below, after summarizing the Ubaye tectonic context, we present a set of 74 focal mechanisms, and we discuss the associated regime of deformation for the swarm area. We then determine the regional stress field and compute the fluid overpressures required to reactivate fault planes. Finally, we discuss our results and propose a comprehensive mechanism for the 2003-2004 episode, in accordance with previous observations and with the results of this study.

\section{Seismotectonic Setting of the 2003-2004 Ubaye Swarm.}

\subsection{Geological and Seismological Background}

[8] The study area is located in the southwestern Alps, in the Ubaye valley, which is one of the most seismically active zones in the French Alps (Figure 1) [Thouvenot and Fréchet, 2006]. 
(a)

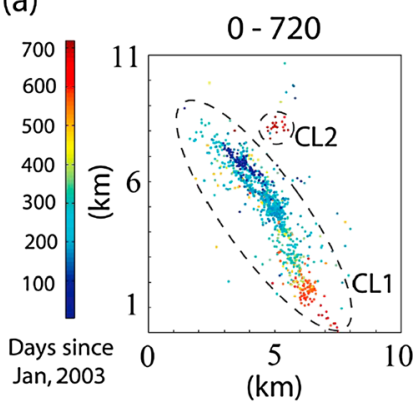

(b)
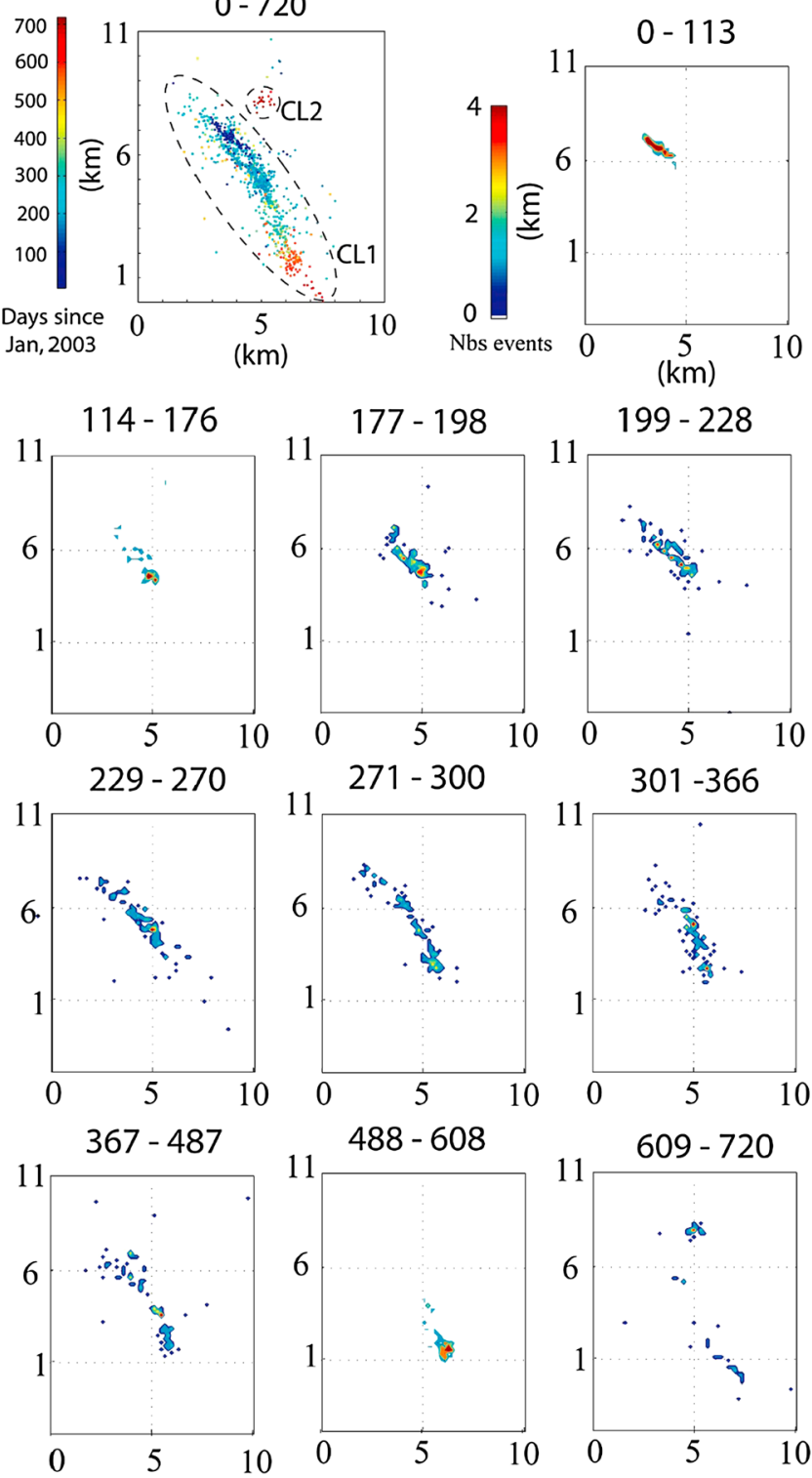

Figure 2. Maps displaying the migration of earthquakes during the 2003-2004 Ubaye swarm based on the seismic relocated catalog of Daniel et al. [2011] (974 events). (a) General map (view) of the swarm. Color scaling refers to the time spanned in days since 1 January 2003. (b) Each panel is a density map for successive sets of 100 earthquakes. Heading numbers correspond to the time interval (in days) used for each map. Reference day is 1 January 2003.

This area is geologically composed of the Argentera Paleozoic crystalline basement, an autochthonous Mesozoic and Cenozoic sedimentary cover (also called Dauphinois cover), and allochthonous units of the Embrunais-Ubaye nappes overlying the sedimentary cover [Faure-Muret, 1955; Kerckhove, 1969; Bogdanoff, 1986; Fry, 1989; Labaume et al., 1989; Sue and Tricart, 2003]. These 1- to $2 \mathrm{~km}$-thick nappes are located in a basement depression north of the Argentera massif. Current seismic activity in the area occurs within this depression, below allochthonous nappes and the autochthonous sedimentary cover, as did the most recent $M_{L}$
4.3 event in February 2012 (Figure 1). Sporadic swarm episodes also occurred in this area: in 1978 [Fréchet and Pavoni, 1979], in 1989 [Guyoton et al., 1990], in 2003-2004 [Jenatton et al., 2007], up to the most recent ongoing episode that started on 26 February 2012. Seismic activity seems well correlated to pluri-kilometric subvertical NW-SE strike-slip faults crosscutting the Argentera massif (Figure 1). Such a relationship to basement faults is attested by the 1959 SaintPaul-sur-Ubaye earthquake focal mechanism [Ménard, 1988; Nicolas et al., 1998] and also by the alignment of hypocenters of the 2003-2004 seismic swarm along a N130 ${ }^{\circ} \mathrm{E}$ striking and $80^{\circ} \mathrm{W}$ dipping plane [Daniel et al., 2011].

[9] Interestingly, the NW-SE fault suggested by this alignment of hypocenters at depth has not been mapped across the autochthonous and allochthonous sedimentary covers [Kerckhove, 1969; Kerckhove et al., 1980; Labaume et al., 1989]. This can be explained by the presence of the Embrunais-Ubaye nappes hiding the fault trace or by a sealing of the NW-SE basement faults by the autochthonous sedimentary cover (Figure 1).

\subsection{The 2003-2004 Seismic Swarm}

[10] The 2003-2004 Ubaye seismic swarm consisted of more than 16,000 events. 1616 events were located using manual pickings of first arrivals, and among these, 974 could be relocated using a double-difference relocation algorithm [Jenatton et al., 2007; Daniel et al., 2011] (Figures 1 and 2). Their magnitudes $\left(M_{L}\right)$ range from -1.3 to 2.7 , with a completeness threshold of 0.2 (Figure 3). The swarm consisted of a 2 year continuous period of nonstationary activity. Figure 3 shows the daily rate of events during the Ubaye swarm and enables us to distinguish three main periods. Period I, spanning from the swarm initiation until day 170, corresponds to the swarm inception. Period II, between days 170 and 340, corresponds to the most intense burst of seismic activity. Period III, starting on day 340 , corresponds to a progressive decay of the overall swarm activity after the most intense seismic burst

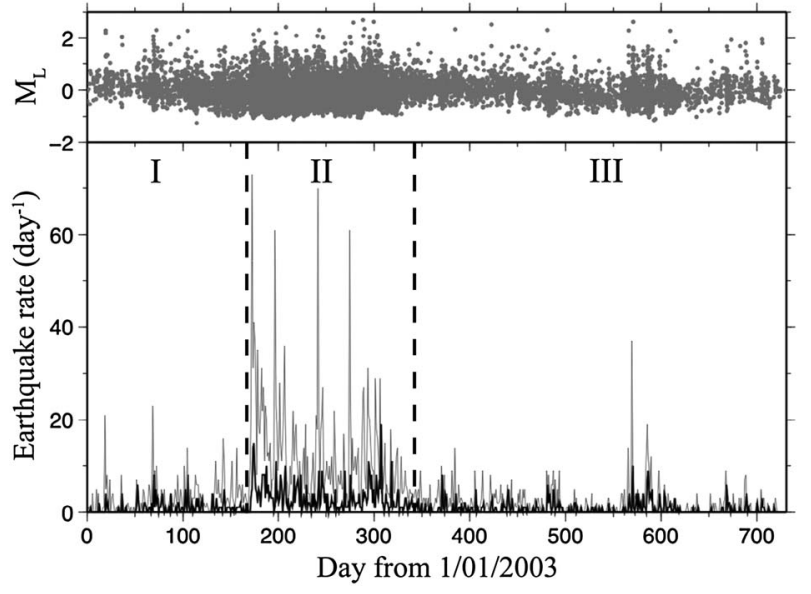

Figure 3. Evolution of the seismicity rate and magnitudes of the 16,147 events detected during the Ubaye swarm (modified from Daniel et al. [2011]). (bottom) Gray curve shows the rate of $M_{L} \geq 0.2$ events taken from the 16,147 detected earthquakes. Black curve shows the rate of $M_{L} \geq 1$ events taken from the 974 relocated earthquakes. Dashed lines divide the swarm episode in three periods: I, swarm inception; II, burst of seismic activity; and III, progressive decay of seismic activity. 
activity. However, it is worth mentioning a lower-intensity seismic burst occurring between days 550 and 610 .

[11] The seismic activity was mainly concentrated along a single NW-SE elongated cluster (denoted as CL1 on Figure 2a). At the end of the sequence, a much smaller secondary cluster (denoted as CL2 on Figure $2 \mathrm{a}$ ) appears north of CL1. Hypocenters range between 3 and $8 \mathrm{~km}$ depth below the sea level [Jenatton et al., 2007]. This depth interval thus tends to confirm that during the swarm, seismic rupture took place only within the crystalline basement (Figure 1c).

[12] Figure 2b displays the swarm chronology. Each panel represents the spatial density of events for each successive temporal set of 100 microearthquakes. The number of 100 events represents $\sim 10 \%$ of the total number of relocated events (974 events) and constitutes a compromise between temporal resolution (short time windows) and a small number of windows. The spatial migration of events is very striking, initiating in the northern part of CL1 and progressively moving to its southern end, with an ultimate activity located nearby, in CL2. The microseismic activity thus began in a confined area $\left(<1 \mathrm{~km}^{2}\right)$ until day 113 and migrated like a shooting star in the southeast direction, while a remanent activity persisted behind the seismic front (Figure 2b). Most of the migration occurred between days 176 and 300, at the time of the main burst of activity (period II). Once the southernmost end of cluster CL1 was reached, this back-front persistent activity progressively decreased from north to south. Toward the end of the crisis, between days 488 and 608, seismic events again focused toward a small area $\left(\sim 1 \mathrm{~km}^{2}\right)$ of CL1. This constituted the second burst of seismic activity. The two seismic bursts thus occurred at two different locations along the main cluster CL1 and presented two different spatiotemporal evolutions. Indeed, while the seismicity clearly migrated southward during the main seismic burst, the second burst presented an activity focused in a small area. Afterward, the activity in cluster CL2 developed between days 609 and 720, without any obvious connection to cluster CL1.

[13] According to Daniel et al. [2011], this migration pattern presented a quasi-diffusive character, which could indicate that fluids may have played a role in driving the swarm migration as described elsewhere [Nur and Booker, 1972; Shapiro et al., 1997; Miller et al., 2004; Cappa et al., 2009].

\section{Focal Mechanisms and Deformation Regime in the Ubaye Area.}

\subsection{Focal Mechanisms}

[14] The 38 focal mechanisms presented in Jenatton et al. [2007] for the year 2003 activity are characterized by normal faulting with a SW-NE extension direction, and by NW-SE right-lateral strike-slip motion. Both regimes agree with other regional structural data. Indeed, the strike-slip regime is consistent with the counterclockwise rotation of the Adriatic microplate relative to Eurasia [Thouvenot and Fréchet, 2006], and the extensional regime can be the result of the isostatic compensation of crustal volumes [Sue et al., 1999]. Based on this set of 38 focal solutions, Leclère et al. [2012] determined the local stress tensor, which is dominated by a strike-slip regime.

[15] In this study, we use an extended set of focal mechanisms by including events that occurred during year 2004 and first-motion polarities for five additional temporary stations deployed in the area between September 2003 and December 2004 (Figures 4 and 5). Inversion of doublecouple focal mechanisms was performed using the FPFIT software [Reasenberg and Oppenheimer, 1985]. The determination of the focal mechanisms based on the first-motion polarities is done by minimizing the misfit function. The misfit values for each focal mechanism are computed by adding the error between observed and theoretical first-motion polarities. If the observed and theoretical polarities are similar, the error is 0 . If the observed polarity is compressional and the theoretical polarity is dilatational, the error is 1 ; vice versa, the error is -1 . The error for each polarity is then weighted as a function of the position of the polarity with respect to the nodal planes. This weighting scheme downweights observations near nodal planes, thereby minimizing the effect of associated inconsistencies, such as those caused by unmodeled refractions. In this study, the focal mechanisms were determined by using at least $13 P$ wave polarities and led to misfit values smaller than 0.3 . The extended data set contains 74 focal mechanisms.

\subsection{Deformation Regimes Inferred From Focal Mechanisms}

[16] In this section, we characterize the type of deformation observed during the Ubaye swarm, based on the approach of Delacou et al. [2004]. Their method introduces an " $r$ " parameter (in degrees) built from the plunge of the $\mathrm{P}$ and $\mathrm{T}$ axes of the focal mechanisms. Pure extensional mechanisms are characterized by a vertical $P$ axis, and their associate " $r$ " value of -90 corresponds to the negative plunge of the $\mathrm{P}$ axis. Conversely, pure compressional mechanisms are characterized by a vertical $\mathrm{T}$ axis, and their associate " $r$ " value of +90 corresponds to the positive plunge value of the T axis. Based on this, negative " $r$ " values between -90 and -65 indicate an extensional tectonic regime while positive " $r$ " values between +90 and +65 stand for a compressional tectonic regime. Moreover, intermediate " $r$ " values between -65 and -15 describe a transtensional tectonic regime while " $r$ " values between +15 and +65 involve a transpressional tectonic regime. Finally, " $r$ " values between -15 and 15 stand for a strike-slip deformation regime.

[17] In the Ubaye area, the tectonic regime of deformation deduced from focal mechanisms is predominantly extensional: $64 \%$ of the data belong to an extensional to transtensional regime, while $20 \%$ belong to a transpressional to compressional regime. However, note that $16 \%$ of the data correspond to a strike-slip regime. Figure 6 a summarizes the relative contribution of each regime of deformation to the whole focal mechanism data set, and Figure $6 \mathrm{~b}$ displays the temporal evolution of deformation during the Ubaye swarm.

[18] Interestingly, all modes of deformation did not undergo the same temporal history (Figure 6b). Indeed, although extensional and transtensional regimes were active during the whole swarm episode, strike-slip deformation was mainly active from the swarm initiation until day 420, while transpressional deformation started at day 240. Period II thus appears to be a period of transition between a period I combining extensional, transtensional, and strike-slip deformation regimes, and a period III described by extensional, transtensional, and transpressional deformation regimes.

[19] Moreover, Figure 6c shows that most of the transpressional and compressional events are located to the 


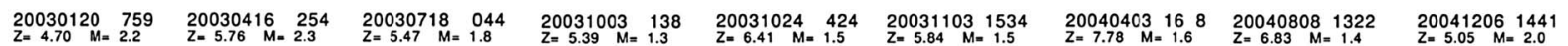
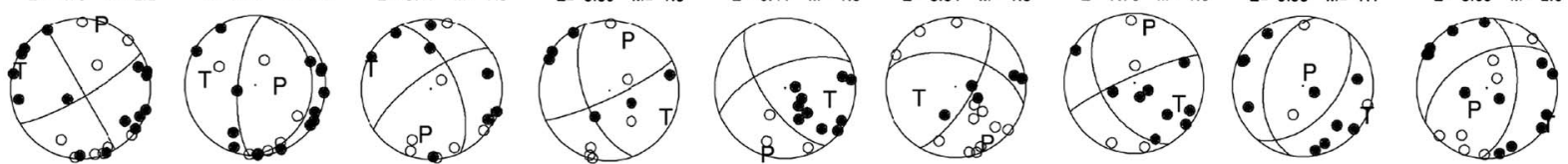

20030120
$Z=4.80$
$M=2.3$$\quad \begin{aligned} & 20030623 \\ & Z=6.26 \\ & M=2.1\end{aligned}$
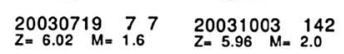

$Z=5.15 \quad 200310251836$

20031115
$Z=4.69$
$M=1.8$

200404162136

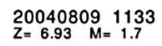

$\mathrm{Z}=5.43 \mathrm{M}=1.8$
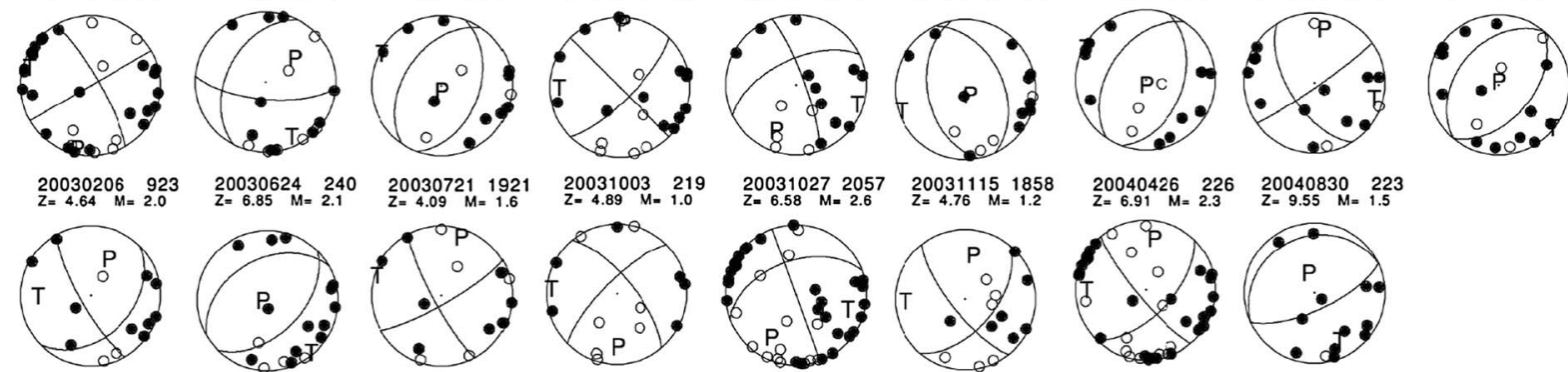

20030206
$Z=4.64$

$\begin{aligned} & 20030624 \\ & Z=6.85\end{aligned}=2.10 \quad 20030721 \quad 1921$

20031003
$z=4.89$
$M=1.0$

200310272057
$Z=6.58 \quad M=2.6$

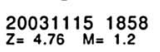

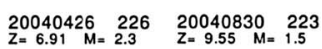
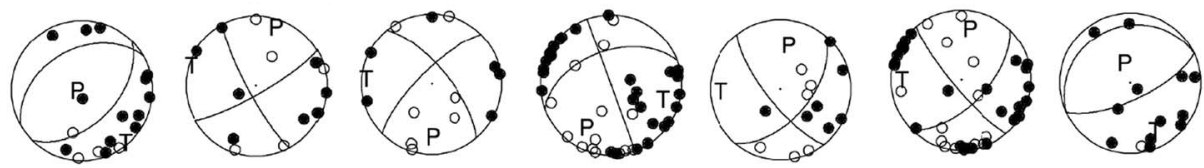

200302061727

20030624
$z=5.42 \mathrm{M}=1.9$

200307272244
$Z=5.17$
$M=2.4$

$\begin{array}{ll}20031006 & 1240 \\ z=6.13 & M= \\ 2.6 & \end{array}$

20031028228
$Z=6.44 \quad M=1.8$

20031213
$Z=6.08$
$M=1.8$

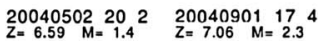
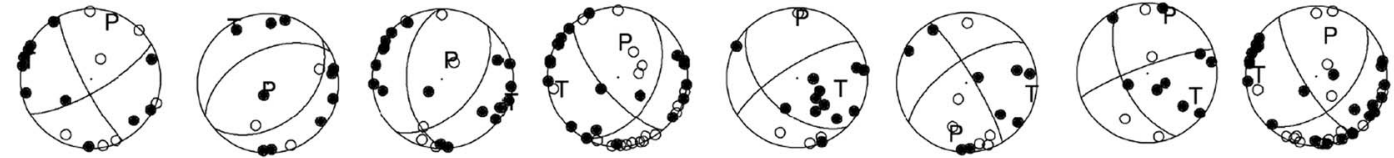

$\begin{aligned} & 20030311 \\ & Z=5.13 \\ & M=2.1\end{aligned} \quad Z=6.34 \quad 200306291739$

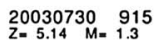

$\mathrm{Z}=4.85 \mathrm{M}=2.3$
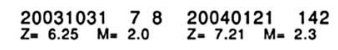

$z=6.86 \quad \mathrm{M}=1.3$

200410302127
$\mathrm{Z}=6.83 \mathrm{M}=\mathrm{ND}$
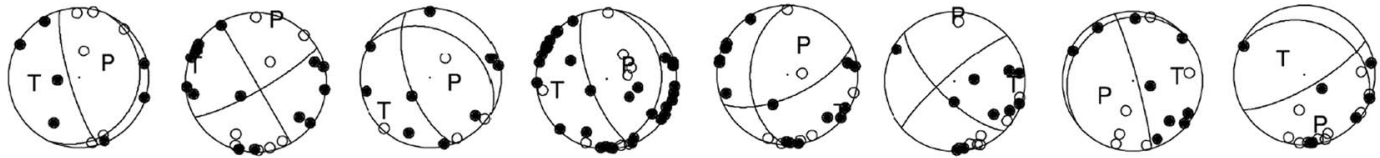

$20030311 \quad 10$
$Z=5.07$
$M=1.9$
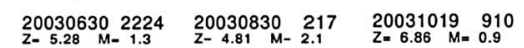

200310311454

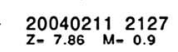

$20040720 \quad 319$
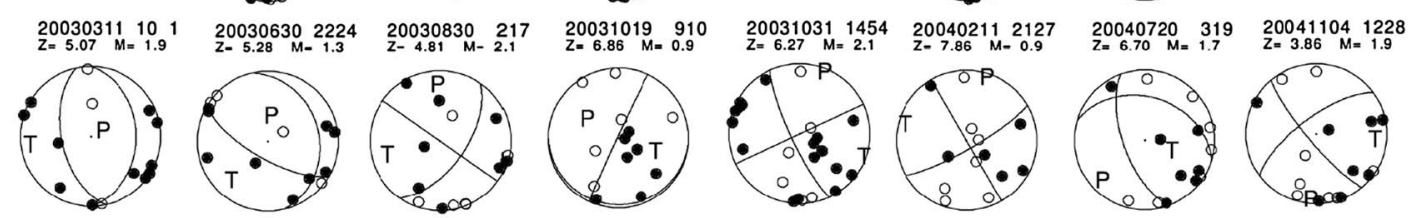

$\mathrm{Z}=5.24_{\mathrm{M}=2.3}^{823}$

$Z=4.79 \mathrm{M}=1.74$

20030831238

$\mathrm{Z}=6.39 \mathrm{M}=1.5$

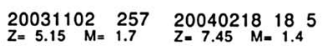
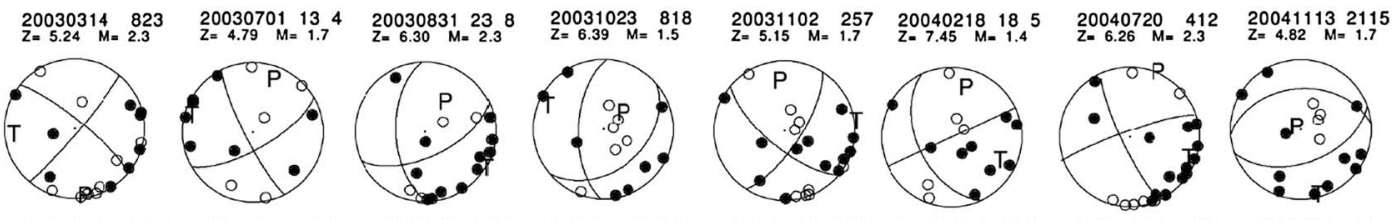

$\mathrm{Z}=5.10_{\mathrm{M}=1.8}^{250}$
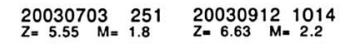

20031023
$z=6.24 \mathrm{M}=2.0$
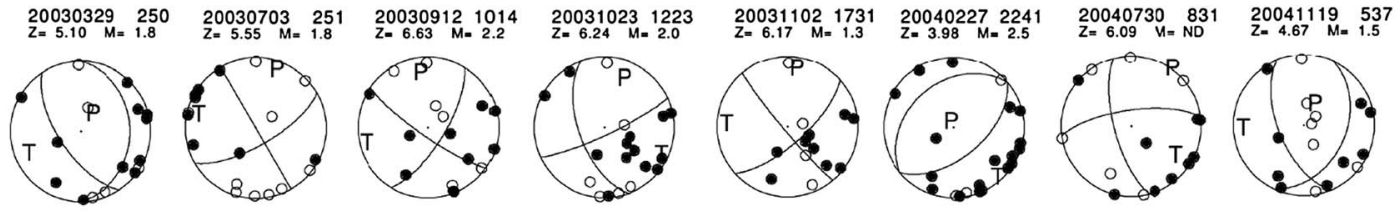

$\mathrm{Z}=5.35 \mathrm{M}=2.0 \quad 223 \quad 200307044^{19} 7$

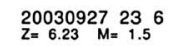

$\mathrm{Z}=6.17 \mathrm{M}=1.8$

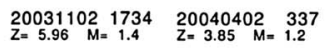

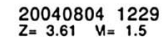

$\begin{aligned} & 20041119 \\ & Z=4.92 \\ & M=\end{aligned}=1.8$
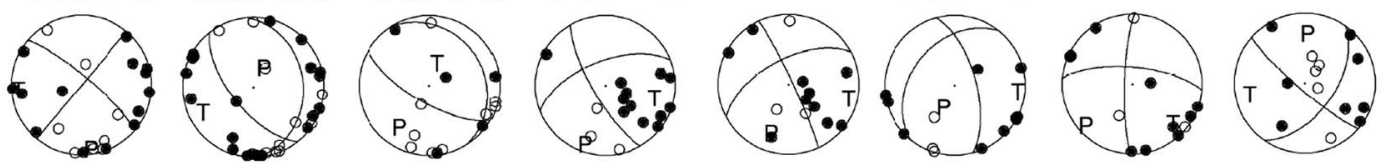

Figure 4. Focal mechanisms (lower hemisphere, equal area projection) for the 74 largest events of the Ubaye swarm. The heading over each diagram indicates the date, origin time, depth, and magnitude of the event.

southeast of cluster CL1 (except for five events located to the northwest). Besides, extensional to transtensional events are mostly located northwest of cluster CL1 (except for seven events located to the southeast).

[20] Finally, $\mathrm{P}$ and $\mathrm{T}$ axes azimuths are homogeneous along the main cluster CL1, with $P$ axes azimuths preferentially oriented N-S to NE-SW and T axes preferentially oriented E-W to NW-SE (Figure 6c). Note that such directions are in good agreement with GPS measurements, which indicate an E-W extension and a N-S shortening [Calais et al., 2002; Delacou et al., 2008; Larroque et al., 2009].

\section{Imaging Overpressurized Areas}

[21] The computation of the fluid overpressure required for the reactivation of fault planes identified from our set of focal 


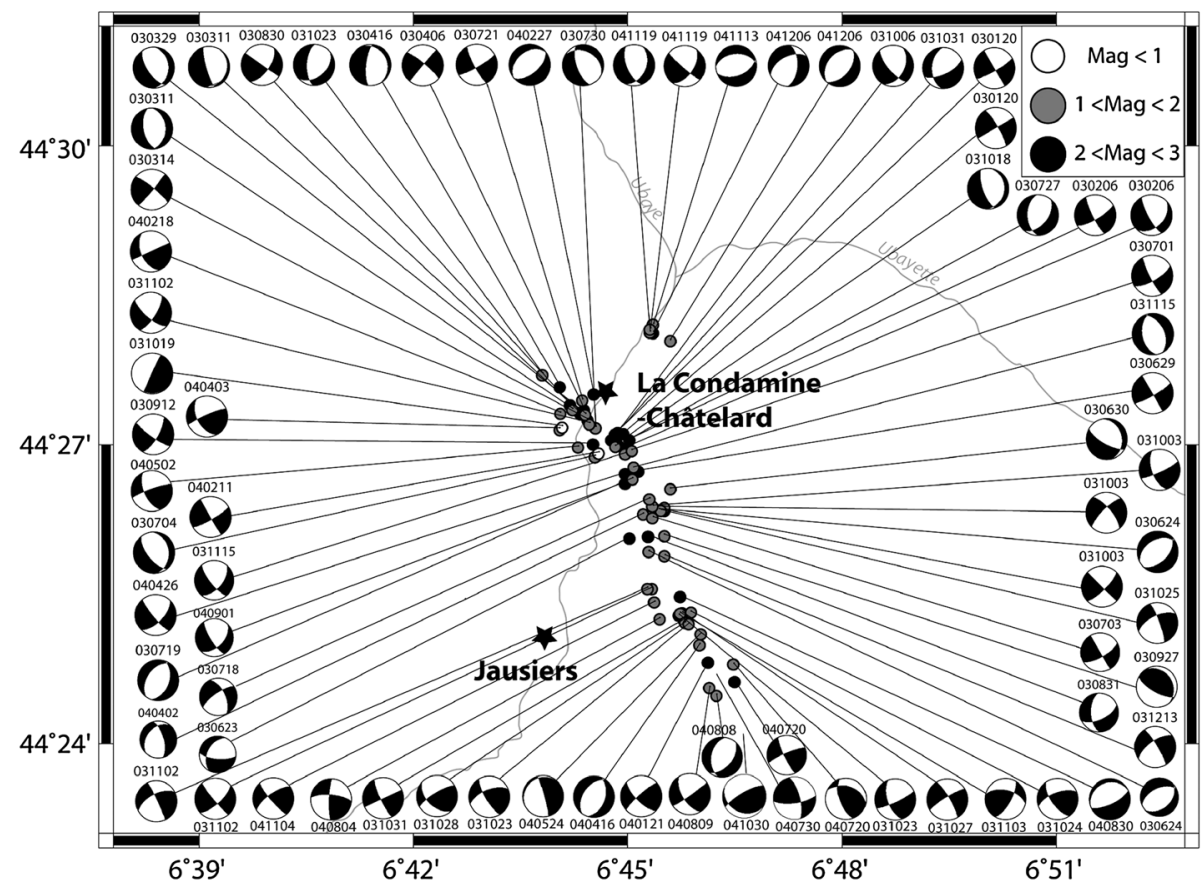

Figure 5. Map of focal mechanisms for the set of 74 events, presented in Figure 4. Filled quadrants stand for compressional first motions; empty quadrants stand for dilatational first motions. Labels over each mechanism indicate the date of occurrence of the event.

mechanisms is based on the Mohr-Coulomb theory [Sibson, 2000; Cox, 2010]. The orientations and relative magnitudes of the three principal stress axes are first determined from published data. Then, the principal stress orientations are used in conjunction with independent structural information to discriminate, for each focal mechanism, the nodal plane corresponding to the active fault plane. Finally, the spatialtemporal fluid overpressure history is computed from the selected fault plane of each focal mechanism using the Mohr-Coulomb theory.

\subsection{Determination of the Principal Stress Axis Orientations and Magnitudes}

[22] We suppose the stress state in the swarm hypocentral region to be Andersonian; that is, one principal stress axis is vertical (and the two others are therefore horizontal). In addition to being supported by seismological and geological evidence, the Andersonian hypothesis allows us to consider the vertical stress axis $\sigma_{2}$ as the lithostatic stress $\sigma_{\mathrm{v}}$.

[23] The orientations of the principal axes of the regional stress tensor in the study area have been extensively analyzed [Béthoux et al., 1988; Labaume et al., 1989; Sue and Tricart, 2003; Delacou et al., 2004; Sanchez et al., 2010; Leclère et al., 2012]. These studies indicate that the maximum horizontal stress axis, $\mathrm{SH}$, is the $\sigma_{1}$ axis and trends $\mathrm{N} 10^{\circ} \mathrm{E} \pm 5^{\circ}$ and that the minimum horizontal stress axis, $\mathrm{Sh}$, is $\sigma_{3}$ and trends $\mathrm{N} 100^{\circ} \mathrm{E} \pm 5^{\circ}$. These principal stress orientations are in good agreement with GPS measurements [Calais et al., 2002; Delacou et al., 2008; Larroque et al., 2009].

[24] The intermediate (vertical) principal stress $\sigma_{2}$ is taken equal to the lithostatic load $\sigma_{\mathrm{v}}: \sigma_{2}=\sigma_{\mathrm{v}}=\rho \mathrm{gz}$, where $\rho$ corresponds to the rock density, taken equal to $2700 \mathrm{~kg} \mathrm{~m}^{-3} ; \mathrm{g}$ stands for the gravitational acceleration; and $\mathrm{z}$ stands for depth. The magnitude of the minimum horizontal principal stress $\sigma_{3}(\mathrm{Sh})$ is constrained from various stress measurements taken from deep boreholes investigations in France [Cornet and Burlet, 1992; Cornet et al., 1997; Evans, 2005], in Germany [Brudy et al., 1997] and in California [Zoback and Healy, 1992] (Figure 7). The choice of these values of $\sigma_{3}(\mathrm{Sh})$ is motivated by a horizontal $\sigma_{3}$ axis having the minimum stress in all these stress measurements and by the availability of in situ stress measurements at depth within the western European crust. In addition, we added the Cajon Pass stress measurements because they come from an area where the tectonic regime is the same as in the study area (strike-slip stress state) and because the $\sigma_{3}$ values are similar to those obtained in France and Germany. We hypothesize that in situ stress conditions in the Ubaye area follow the trend presented on Figure 7. The magnitude of $\sigma_{3}$ (Sh) corresponds to the best fit of measurements between 100 and $7000 \mathrm{~m}$ depth where $\sigma_{3}=a z-b$, with $\mathrm{z}$ being the depth, $a=21 \mathrm{MPa} / \mathrm{km}, \mathrm{b}=5 \mathrm{MPa}$, and with a correlation coefficient $\mathrm{R}$ of 0.98 . The magnitude of $\sigma_{1}(\mathrm{SH})$ is obtained from the magnitudes of $\sigma_{2}$ and $\sigma_{3}$, and from the stress shape ratio $\Phi=\left(\sigma_{2}-\sigma_{3}\right) /\left(\sigma_{1}-\sigma_{3}\right)$, by the relation $\sigma_{1}=\left(\sigma_{3}\right.$ $\left.(\Phi-1)+\sigma_{2}\right) / \Phi$.

[25] The stress/shape ratio of the study area is equal to 0.75 and was obtained from the Slick program [Michael, 1987] applied to the 74 focal mechanisms. The Slick program determines the stress/shape ratio, $\Phi$, by performing a series of stress inversions (using a grid-search algorithm), so as to find the optimal $\Phi$ value minimizing the difference between the slip vector and the resolved shear stress vector on each of the fault planes.

[26] This ratio is in good agreement with the 0.76 estimate of Delacou et al. [2004] obtained from independent data (focal mechanisms located over a broad area encompassing the study area of this paper). 

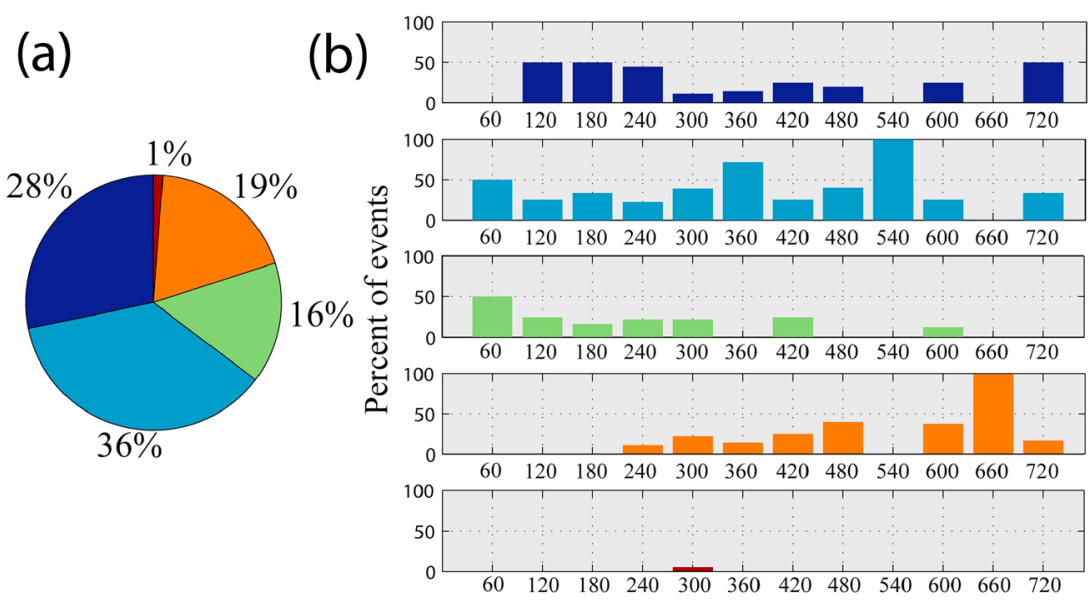

Day from $1 / 01 / 2003$

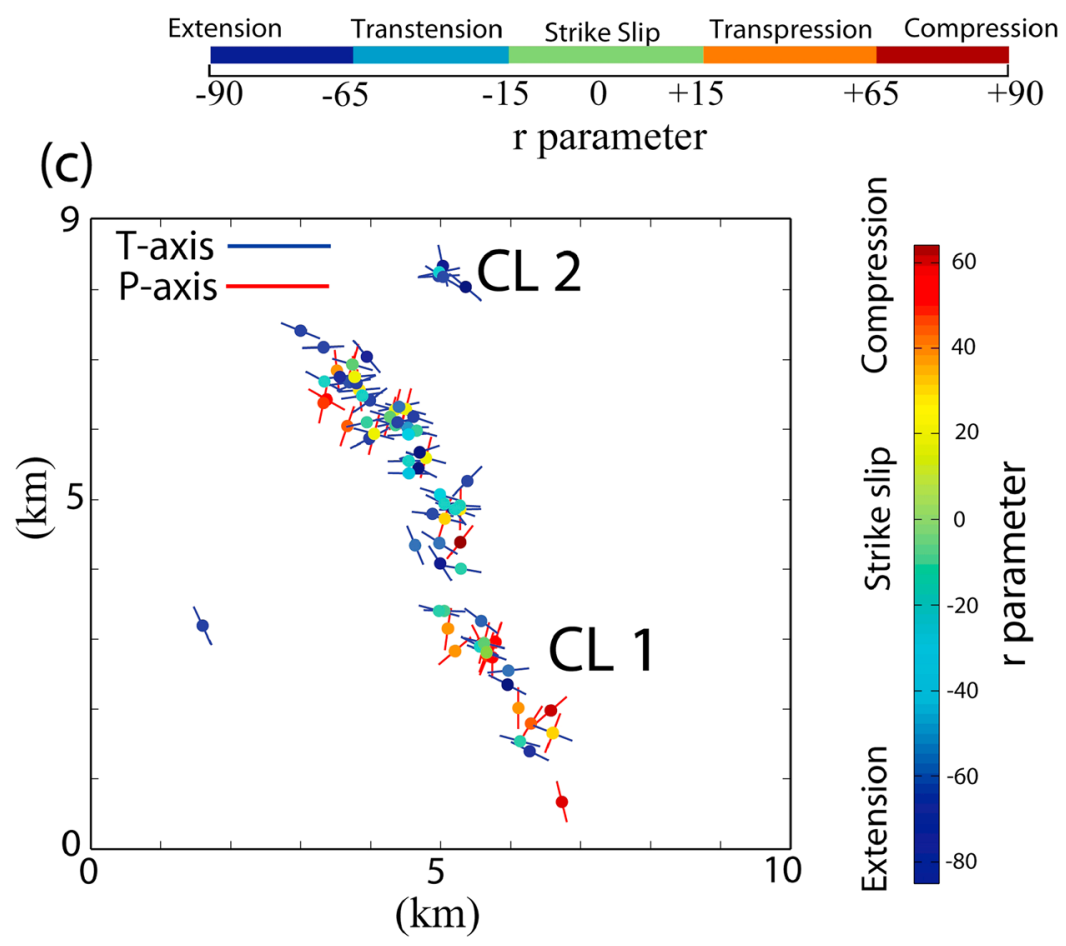

Figure 6. Regime of deformation based on the 74 focal mechanisms presented in Figures 4 and 5. (a) Pie box displaying the relative contribution of individual tectonic regimes to the deformation of the Ubaye area. (b) Bar plots showing the temporal variations of individual deformation regimes. (c) Map of principal deformation directions ( $\mathrm{P}$ and $\mathrm{T}$ axes) during the Ubaye swarm. Lines correspond to the projection at the surface of $\mathrm{P}$ axis directions (red lines) and $\mathrm{T}$ axis directions (blue lines). Filled circles stand for events' epicentral location and are colored as a function of their respective $r$ parameter value (based on the $\mathrm{P} / \mathrm{T}$ axes dips, see text).

\subsection{Discrimination of Active Nodal Planes}

[27] The selection of the appropriate nodal plane for each double-couple mechanism is based on the misfit angle $\alpha$ between the theoretical and observed slip vectors and on the main orientation of the regional faults. The theoretical slip vector corresponds to the orientation of the shear stress direction, $\tau$, on the fault plane. The observed slip vector is given by the rake angle of the focal mechanism. For each nodal plane of a particular focal mechanism, the computation of the misfit angle $\alpha$ is based on the principal stress axes orientations, the stress shape ratio, $\Phi$, and its rake angle. If the two misfit angles, $\alpha$, for both nodal planes, are larger than the threshold value $\alpha_{\text {th }}$ equal to $30^{\circ}$, then the focal mechanism is discarded and will not be used in the analysis. Indeed, an $\alpha$ angle greater than $\alpha_{\text {th }}$ indicates that, for the concerned event, the slip is not controlled by the regional stress field, but rather by local stress perturbations. If only one nodal plane has an angle $\alpha<\alpha_{\text {th }}$, it is then considered as the active nodal (fault) plane. If the two nodal planes have angles $\alpha<$ $\alpha_{\mathrm{th}}$, the nodal plane striking most closely to the directions of the regional faults (NW-SE to N-S) will be retained. Following this selection procedure, 19 events are discarded from the original data set of 74 focal mechanisms, leading to a final set of 55 fault planes. 


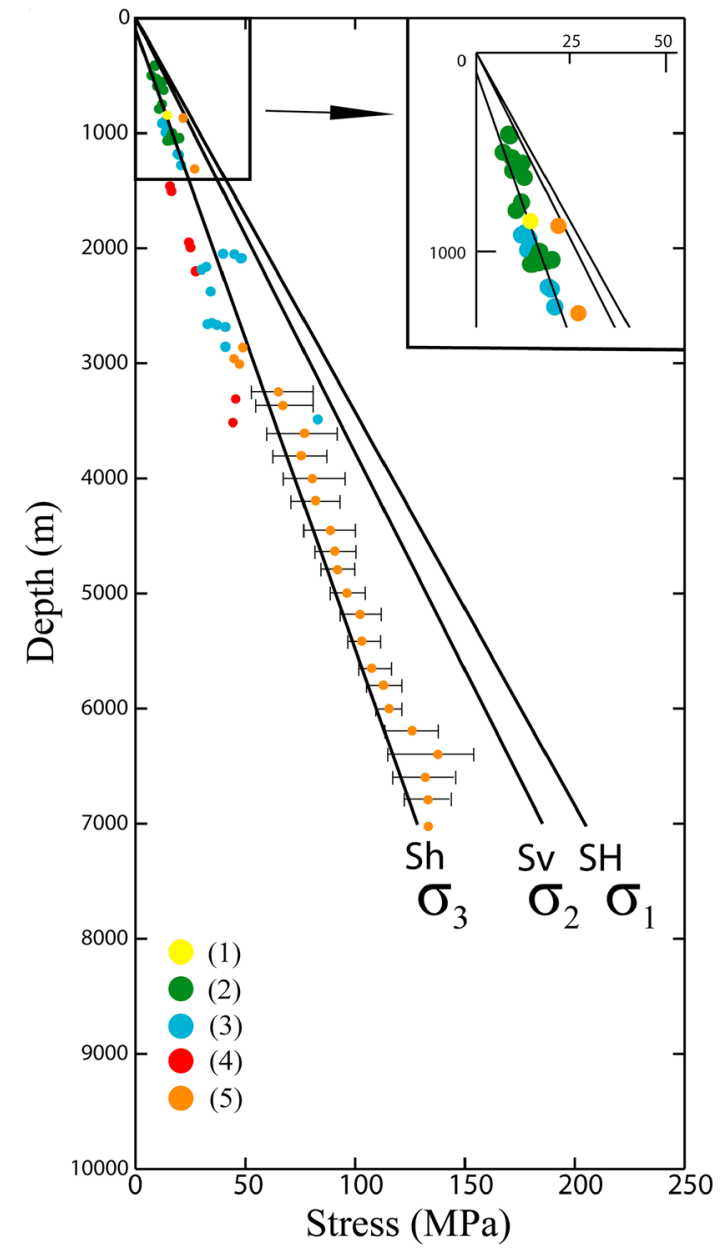

Figure 7. Dependence of principal stress magnitudes on depth for the Ubaye area. Values for the minimal horizontal stress Sh are taken from borehole measurements. The magnitude of the minimal principal stress $\sigma_{3}(\mathrm{Sh})$ corresponds to the best fit of measurements between 100 and $7000 \mathrm{~m}$ depth, where $\sigma_{3}=a z-b$, with $z$ being the depth, $a=21 \mathrm{MPa} / \mathrm{km}$, $\mathrm{b}=5 \mathrm{MPa}$, and with a correlation coefficient $\mathrm{R}$ of 0.98 . The intermediate principal stress $\sigma_{2}=\sigma \mathrm{V}$ is taken equal to the lithostatic load, and the maximal horizontal stress $\mathrm{SH}$ is computed from Sh, $\sigma \mathrm{v}$, and the stress shape ratio $\Phi$. (1) Cornet et al. [1997], $40 \mathrm{~km}$ south of Ubaye area; (2) Cornet and Burlet [1992], various areas in France; (3) Zoback and Healy [1992] at Cajon Pass (California); (4) Evans [2005] at Soultz-sous-Forêts (France); and (5) Brudy et al. [1997] at KTB (Germany).

[28] Figure 8 shows the projection of these 55 fault planes on a Mohr-Coulomb diagram. The Mohr-coulomb diagram was done using a tensile strength $\mathrm{T}$ of $17.5 \mathrm{MPa}$ (consistent with granitoids, [see Amitrano and Schmittbuhl, 2002]), a coefficient of static friction for the failure envelope, $\mu_{\mathrm{s} \text {,intact }}$, of 0.75 , and a static friction coefficient for reactivation, $\mu_{\mathrm{s}}$, of 0.4 used to compute the pore fluid pressure $P f$. The value of $\mu_{\mathrm{s}}$ is in agreement with the presence of phyllosilicate-rich gouges in core zones of the Argentera massif NW-SE faults, located further south, in continuity with the Ubaye swarm trend [Leclère et al., 2012].This diagram also presents the failure envelope and the reactivation envelope at initial conditions (i.e., with hydrostatic fluid pressure). Note that the location and diameter of the three Mohr circles come from stress values presented on Figure 7 , assuming $\sigma_{1} / \sigma_{3}$ and stress shape $\Phi$ ratios constant with depth. On the Mohr-Coulomb diagram (Figure 8), fault plane projections (gray dots) located above the reactivation envelope can be reactivated without pore fluid overpressure (pore pressure above hydrostatic fluid pressure). On the contrary, fault plane projections located below the reactivation envelope (black dots) require pore fluid overpressures to be reactivated. This diagram also shows the projections of four fault planes (unfilled circle symbols), which cannot be reactivated because the circle $\left(\sigma_{1}, \sigma_{3}\right)$ will reach the failure envelope before the four fault planes reach the reactivation envelope.

\subsection{Computation of Fluid Overpressure}

[29] By projecting the three principal stress axes orientation and magnitude on the selected fault planes, one can compute the shear stress $\tau$ and normal stress $\sigma_{\mathrm{n}}$ acting on each plane using Cauchy's equations [Jaeger et al., 2007]:

$$
\begin{gathered}
\tau^{2}=\left(\sigma_{1}-\sigma_{2}\right)^{2} 1^{2} m^{2}+\left(\sigma_{2}-\sigma_{3}\right)^{2} m^{2} n^{2}+\left(\sigma_{3}-\sigma_{1}\right)^{2} 1^{2} n^{2} \\
\sigma_{n}=l^{2} \sigma_{1}+m^{2} \sigma_{2}+n^{2} \sigma_{3}
\end{gathered}
$$

where $l, m$, and $n$ are the direction cosines between the normal $\boldsymbol{n}$ of the fault plane and the principal stress axes $\sigma_{1}, \sigma_{2}$, and $\sigma_{3}$ respectively.

[30] The pore fluid pressure, $P f$, required to reactivate a fault plane can then be computed using Amontons' law [Amontons, 1699]:

$$
\tau=\mu_{s}\left(\sigma_{\mathrm{n}}-P f\right)
$$

where $\mu_{\mathrm{s}}$ is the coefficient of static friction. Hence,

$$
P f=\frac{\mu_{s} \sigma_{n}-\tau}{\mu_{s}}
$$

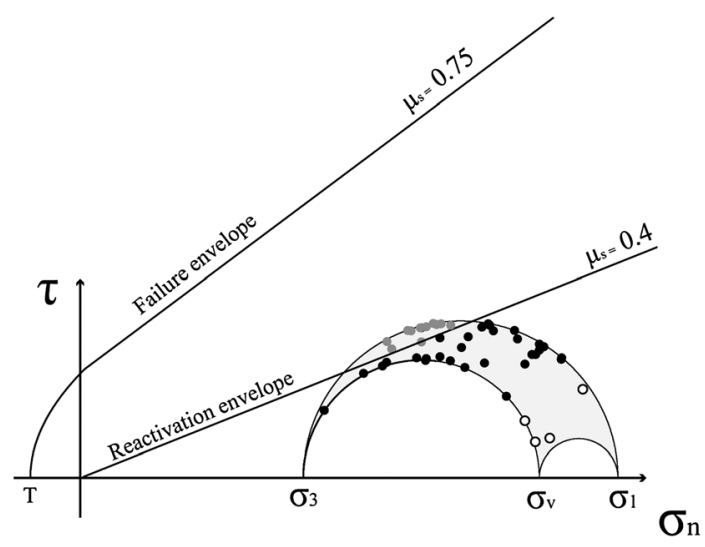

Figure 8. Mohr-Coulomb diagram displaying the failure and reactivation envelopes with projections of the 55 selected fault planes (dots). Gray dots stand for fault planes reactivated without need of excess pore pressure, while black dots correspond to mechanisms requiring an excess pore pressure to be reactivated. Unfilled circles correspond to fault planes that cannot be reactivated because the great circle $\left(\sigma_{1}, \sigma_{3}\right)$ will reach the failure envelope before the fault planes reach the reactivation envelope. 
[31] Depending on the values of $\mu_{\mathrm{s}}$ and on the differential stress $\left(\sigma_{1}-\sigma_{3}\right)$, the reactivation of a preexisting fault may not be possible as a new optimally oriented fault may be created before the reactivation process takes place. Thus, in order to test if a target fault plane was reactivated, we first compute the pore fluid pressure $\left(P f_{\text {rupt }}\right)$ required to create a new fault using the Mohr-Coulomb theory and the Griffith failure criterion. If $P f_{\text {rupt }}>P f$, the target fault plane can be reactivated. Conversely, if $P f>P f_{\text {rupt }}$, the target fault cannot be reactivated, and a new fault is created more favorably under the given regional stress conditions.

[32] Under excess pore pressure conditions, the creation of new faults or failures can take place according to three modes:

[33] 1. "Extensional mode failure" involves the generation of fractures perpendicular to the orientation of $\sigma_{3}$, with tensile opening of the fracture parallel to $\sigma_{3}$. Following Secor [1965], it is assumed that extensional failure occurs only for stress conditions in which $\left(\sigma_{1}-\sigma_{3}\right)<4 \mathrm{~T}$, with $\mathrm{T}$ being the tensile strength of the intact rock. In that case,

$$
P f_{\text {rupt }}=\sigma_{3}+\mathrm{T}
$$

[34] 2. "Hybrid extensional-shear failure" involves components of shear and dilation. Fracture formation occurs only for stress conditions in which $4 \mathrm{~T}<\left(\sigma_{1}-\sigma_{3}\right)<5.66 \mathrm{~T}$ [Hancock, 1985]. In this case,

$$
P f_{\text {rupt }}=\frac{8 \mathrm{~T}\left(\sigma_{1}+\sigma_{3}\right)-\left(\sigma_{1}-\sigma_{3}\right)^{2}}{16 \mathrm{~T}}
$$

[35] 3. "Shear failure" involves displacement parallel to the shear fracture surface. Fracture creation occurs only for stress conditions in which $\left(\sigma_{1}-\sigma_{3}\right)>5.66 \mathrm{~T}$. In this case,

$$
P f_{\text {rupt }}=\frac{C-\tau_{\text {optimal }}}{\mu_{s, \text { intact }}}+\sigma_{n, \text { optimal }}
$$

where $\mathrm{C}=2.083 \mathrm{~T}$ [Jaeger et al., 2007], $\mu_{\mathrm{s} \text {,intact }}$ is the coefficient of static friction of the failure envelope, and $\tau_{\text {optimal }}$ and $\sigma_{\text {n,optimal }}$ are the shear and normal stresses, respectively, for which the Mohr-Coulomb circle $\left(\sigma_{1}, \sigma_{3}\right)$ is tangent to the failure envelope $\tau=\mathrm{C}+\mu_{\mathrm{s} \text {,intact }} \sigma_{\mathrm{n}}$ :

$$
\begin{gathered}
\tau_{\text {optimal }}=\frac{\left(\sigma_{1}-\sigma_{3}\right)}{2} \sin \left(2 \theta_{r, \text { optimal }}\right) \\
\sigma_{n, \text { optimal }}=\frac{\left(\sigma_{1}+\sigma_{3}\right)}{2}-\frac{\left(\sigma_{1}-\sigma_{3}\right)}{2} \cos \left(2 \theta_{r, \text { optimal }}\right)
\end{gathered}
$$

$\theta_{\mathrm{r} \text {,optimal }}$ is the angle between the optimal oriented shear plane and $\sigma_{1}$ [Sibson, 1985] and is given by

$$
\theta_{r, \text { optimal }}=\frac{1}{2} \tan ^{-1}\left(\frac{1}{\mu_{s, \text { intact }}}\right)
$$

[36] The pore fluid pressures $P f$ and $P f$ rupt are then expressed as fluid overpressure $\partial P f$ and $\partial P f$ rupt by subtracting the hydrostatic fluid pressure $\rho g z$ (where the water density $\rho$ is taken equal to $1000 \mathrm{~kg} \mathrm{~m}^{-3}$ ).

\subsection{Fluid Overpressure for Focal Mechanisms of the Ubaye Swarm}

[37] Following the methodology detailed above, the fluid overpressure $\partial P f$ and $\partial P f_{\text {rupt }}$ are computed for each of the
55 selected fault planes (Figure 9). We consider this set of 55 focal mechanisms to be representative of the whole swarm activity. These mechanisms are indeed well distributed in space, along the two clusters CL1 and CL2, with at least one focal mechanism per square kilometer. In addition, they span the 2 year period of seismic activity, presenting only a limited time gap of 90 days between successive mechanisms. The uncertainties on overpressure estimates (error bars) are obtained by rotating the stress tensor within its accuracy limits $\left( \pm 5^{\circ}\right)$.

[38] Figure 9a shows, for each mechanism, the fluid overpressure $\partial P f$ required to reactivate a preexisting fault as a function of the pressure excess $\partial P f_{\text {rupt }}$ required to create a new fault. Thus, the oblique line in Figure $9 \mathrm{a}$ corresponds to the failure envelope of the intact rock with $\partial P f_{\text {rupt }}=\partial P f$. This envelope delimits two domains: (1) an upper domain where a new fault formation is more likely $\left(\partial P f_{\text {rupt }}<\partial P f\right)$ and (2) a lower domain where faults can be reactivated. Among the 55 selected fault planes, four fault planes are located in the upper domain (Figure 9a). These solutions are discarded because $\partial P f$ cannot exceed $\partial P f$ rupt .Indeed, $\partial P f_{\text {rupt }}$ is the maximum value that $\partial P f$ can reach, leading to the formation of a new fault. The occurrence of these four planes may be more likely explained by local stress perturbation rather than by fluid overpressure.

[39] The remaining 51 mechanisms are then associated with their overpressure values, and they vary through time between 0 and $55 \mathrm{MPa}$ (Figure 9b). Interestingly, the three time periods identified from the seismicity time series seem also consistent with respect to the $\partial P f$ overpressure time history (Figure 3 ). During period I, $\partial P f$ is approximately constant and close to $35 \mathrm{MPa}$. During period II, $\partial P f$ varies from small values up to its maximum (55 MPa). Finally, period III is characterized by lower values, with all mechanisms being associated with overpressures lower than $20 \mathrm{MPa}$, except for the first event in this period. Recalling that $\partial P f$ estimates are obtained independently from the seismicity rate time series, their good fit can be interpreted as fluid overpressure in the fault zones driving seismic activity. Here we show that the swarm inception (period I) is characterized by low seismic activity and moderate fluid overpressure (35 MPa). Period II is characterized by a burst of seismic activity, by large fluid overpressures (up to $55 \mathrm{MPa}$ ), and by larger pressure instabilities. Note that the time history of fluid overpressure $\partial P f$ does not present any sharp change at the beginning of period II, as is observed on the seismicity rate history (Figure 3). This could be induced by the discontinuous character of the focal mechanism data set. The data set shows a gap coincident with the beginning of period II. Thus, here we cannot investigate precisely any sharp change in fluid overpressure. Due to this limitation, our analysis presents a rather smooth evolution of overpressure in period II. Lastly, period III is associated to a progressive decay of activity with low fluid overpressures (below $20 \mathrm{MPa}$ ).

[40] The general evolution of fluid overpressures during the Ubaye swarm shows a reasonable agreement with the findings by Daniel et al. [2011]. These authors showed that an increase in fluid overpressure was very likely during the main burst of seismic activity by using an independent technique based on a preliminary seismicity rate declustering and a subsequent modeling of changes in effective normal stress based on rate-and-state friction laws [Dieterich, 1994; Dieterich et al., 2000]. 
(a)

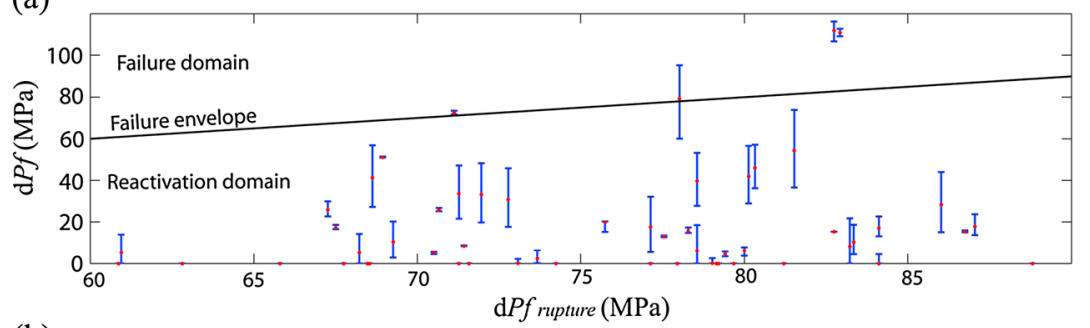

(b)

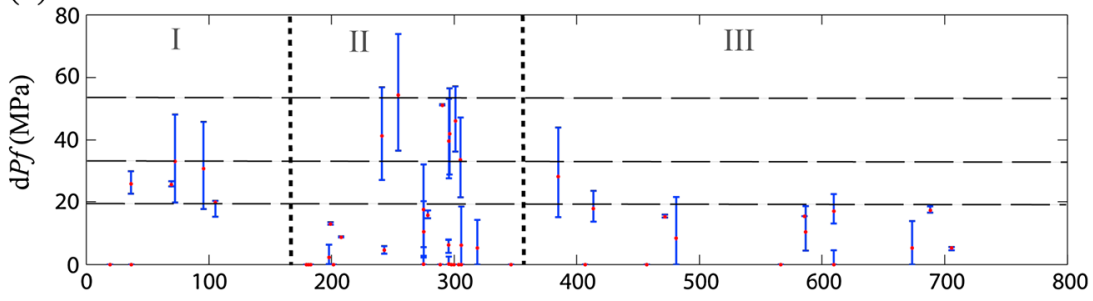

(c)

Day from $1 / 01 / 2003$

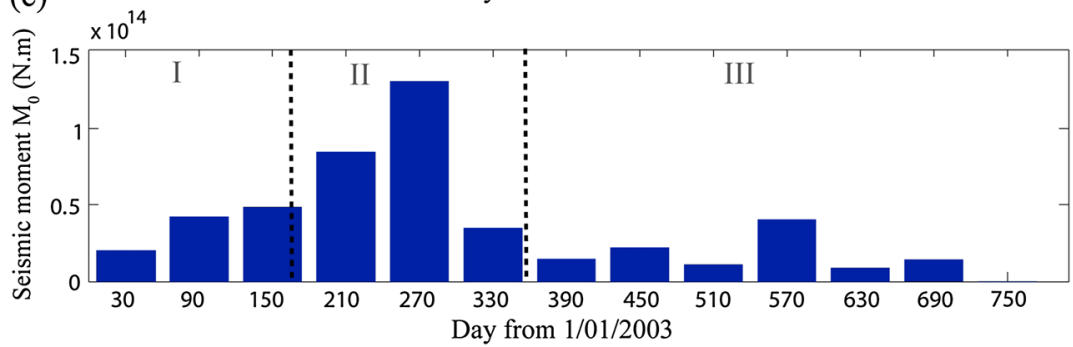

Figure 9. Fluid overpressure variations for the 55 selected focal mechanisms. (a) Comparison of fluid overpressure $\partial P f$ associated with a fault reactivation process versus fluid overpressure $\partial P f$ rupt required for the creation of a new fault. Red dots stand for the $\partial P f$ value obtained using a $\mathrm{N} 10^{\circ} \mathrm{E}$ orientation for the s1 axis, and bars represent the uncertainties on $\partial P f$. The transition between the reactivation domain (below) and the fault creation domain is denoted by the continuous line. Note that the four fault events located above the transition line are later discarded from the overpressure analysis, as they cannot be reactivated. (b) Time series of fluid overpressure for the 51 reactivated focal mechanisms. Time is expressed in days elapsed since 1 January 2003. (c) Cumulative seismic moment in successive two month time windows during the swarm. Time axis corresponds to the median date, in number of days elapsed since 1 January 2003 for each time window.

[41] Besides, the ranges of $\partial P f$ obtained here are similar to the fluid overpressure estimate of $50 \mathrm{MPa}$ obtained by Kurz et al. [2004] from a finite element modeling of the Vogtland/Western Bohemia earthquake swarm. Our value of $25 \mathrm{MPa}$ during the swarm initiation is also similar to the value of $30 \mathrm{MPa}$ found by Hainzl et al. [2012] during the initiation of the 2008 Western Bohemia swarm using stress changes and hydrofracture models.

[42] Our minimal $\partial P f$ estimate of $20 \mathrm{MPa}$ is also in the range of fluid overpressure obtained by Leclère et al. [2012] for the reactivation of a $\mathrm{N} 130^{\circ} \mathrm{E}$ fault segment in Ubaye. These authors reported values between 7 and $26 \mathrm{MPa}$ using a similar approach based on a 2D MohrCoulomb analysis [Cox, 2010]. Daniel et al. [2011] report a smaller difference $(8 \mathrm{MPa})$ between the beginning of the swarm and the burst of seismic activity (around day 250), compared with the $\sim 20 \mathrm{MPa}$ difference for the same time interval in this study. Although these estimates are of the same order of magnitude, the discrepancy is probably related to the smoothing over large time windows and to the arbitrary setting of some of the rate-and-state model parameters in the analysis of Daniel et al. [2011].
[43] The $\partial P f$ estimates obtained here are also similar to those found by Terakawa et al. [2010] for the $M_{w} 6.3$ L'Aquila 2009 earthquake and aftershock sequence using a similar Mohr-Coulomb analysis. The L'Aquila overpressure estimates range between 20 and $50 \mathrm{MPa}$. Despite contrasted magnitudes, the similarity between the L'Aquila and the Ubaye overpressure estimates suggests that the values of fluid overpressures cannot be connected directly to the size of earthquakes. However, on Figure 9c, the evolution of the cumulative seismic moment for successive time windows of two months was estimated by using Bakun's [1984] relationship between $M_{L}$ and the seismic moment $M_{0}$,

$$
\log _{10} M_{0}=1.2 M_{L}+10
$$

[44] This shows that the evolution of the cumulative seismic moments is similar to the evolution of the fluid overpressures. Indeed, at the inception of the swarm, the moderate $\partial P f$ values $(35 \mathrm{MPa})$ fit with the moderate seismic moments released during the same time period, with values mainly close to $410^{13} \mathrm{Nm}$. Then, the evolutions of the seismic moments $M_{0}$ and the fluid overpressures $\partial P f$ have similar trends with 

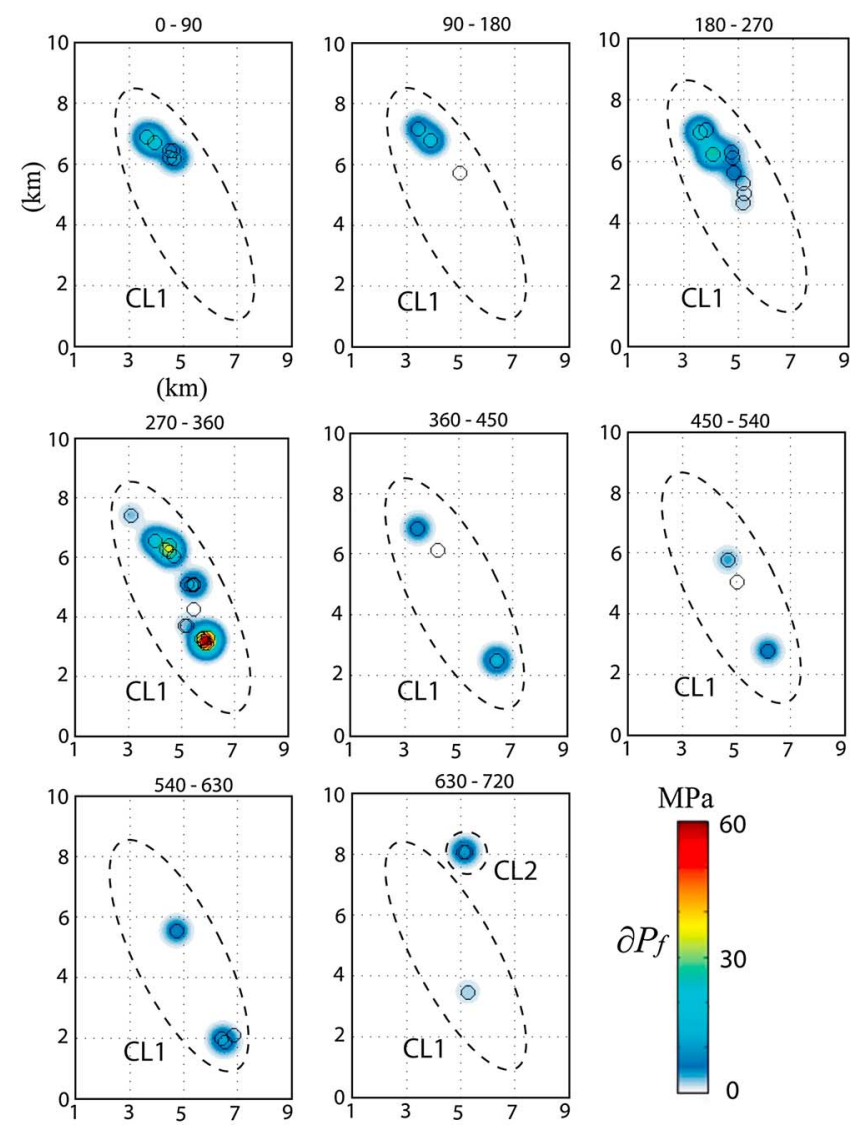

Figure 10. Evolution of fluid overpressure $\partial P f$ during the Ubaye swarm. Each panel displays a map view of fluid overpressure for successive 90 day time intervals. Color scaling is a function of fluid overpressure. Heading numbers display the first and last days of each time interval. Circles correspond to epicenters of focal mechanisms used for $\partial P f$ computation.

highest values of $M_{0}$ and $\partial P f$ reached at the same time (around days 250-270), followed by a simultaneous progressive decrease of the $\partial P f$ and $M_{0}$ values down to their mean lowest values at the end of the swarm activity.

\subsection{Spatial Evolution of Fluid Overpressure}

[45] Figure 10 shows the spatial distribution through time of the fluid overpressure $\partial P f$ computed from focal mechanisms. This map was created by color-coding the epicentral locations of our set of mechanisms as a function of the associated overpressures. The picture was smoothed by using a Gaussian interpolation method between $\partial P f$ values. The swarm episode, spanning from 1 January 2003 to 31 December 2004 is divided into eight periods. Thus, on Figure 10, each map shows the distribution of fluid overpressure required for reactivation, computed for successive 90 day time intervals. Circles also indicate epicenters of focal mechanisms for each period.

[46] The two clusters CL1 and CL2 have recorded significant fluid overpressures during the Ubaye swarm. The three time intervals (I to III) defined in Figure 3 correspond to time divisions for the spatial evolution of fluid overpressure (Figure 10). Period I (between days 0 and 170), linked with the inception of seismic activity, is characterized by the appearance of fluid overpressure within a small area $\left(2-3 \mathrm{~km}^{2}\right)$ located north of CL1. Most of the overpressure migration along CL1 occurred during period II (between days 170 and 340). At first, fluid overpressuring progressively developed southward, between days 180 and 270. Afterward, and until day 360 , it reached its maximum values in two locations apparently disconnected from each other, and also disconnected from the initial locus (north of CL1) of fluid overpressuring. Finally, period III (after day 340) marked the progressive overpressure shutdown. Indeed, the last four panels share a common pattern composed of clearly distinct spots of low-amplitude overpressure. The northern spot vanished first, before the spot located south of CL1, and before the ultimate start of overpressure in CL2. Interestingly, the general trend of fluid overpressure seems in good agreement with the seismicity rate displayed on Figure 3. Moderate and localized fluid overpressure accompanies the swarm initiation. Then a considerable fluid pressure buildup progressively takes place southward, resulting in a high production of microseismic events. The progressive decrease of the earthquake rate is finally associated to a long-lasting ( 1 year long) dissipation of fluid overpressure.

[47] Figure 11 summarizes the cumulative history of $\partial P f$ fluid overpressure on a 3D diagram. Diagram faces are projections of the overpressure spot locations in map view and in two cross sections parallel and perpendicular to the cluster CL1 elongation. Red dashed lines identify the contours of two zones that underwent high overpressures during the swarm. These zones are also distinguishable at depth. They

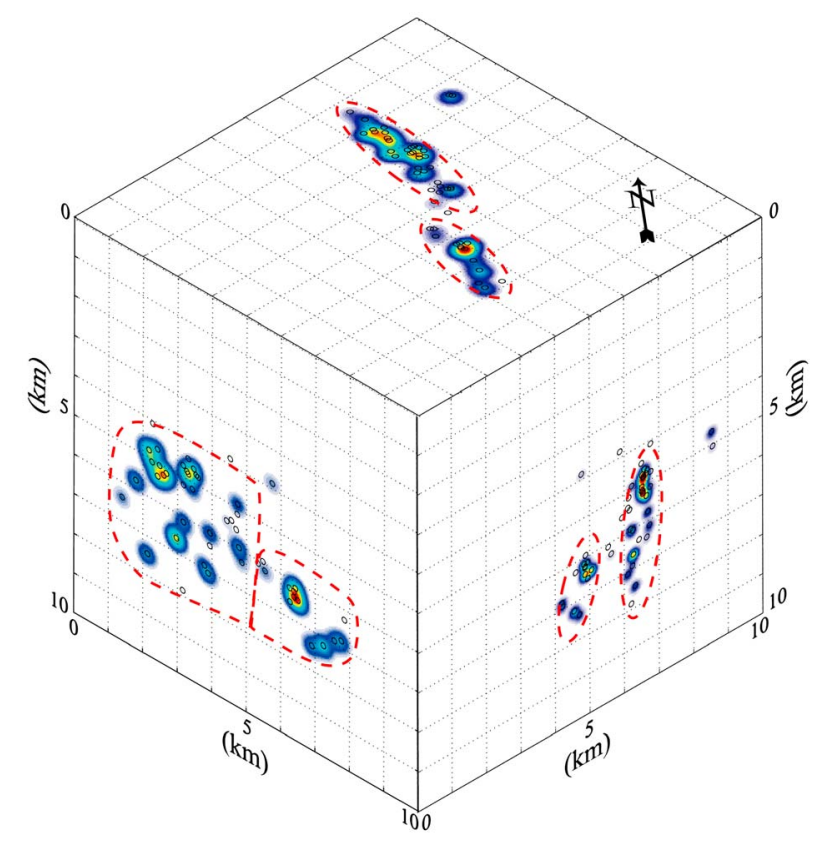

Figure 11. 3D diagram showing the cumulative distribution of $\partial P f$ overpressure for the Ubaye swarm. The top side of the cube is a map view of fluid overpressure, the left side is a cross section parallel to CL1 elongation, and the right side is a cross section perpendicular to CL1 elongation. Circles stand for the projection of the 51 focal mechanisms used in the study. Red dashed contours correspond to high overpressure zones discussed in section 4. Depth is expressed relatively to the sea level. 
clearly indicate that overpressuring took place within the crystalline basement, below the sedimentary cover. The NW-SE planar orientation of such high-pressure zones is parallel to the regional faults and suggests the possible implication of distinct fault segments during the swarm. Fluid overpressure buildup in two distinct zones and at different periods could also suggest that these parallel (or nearly parallel) fault segments could have accommodated independently a similar driving mechanism from January 2003 to December 2004. These two zones are separated by a well-identified gap of fluid overpressure, and therefore, the focal mechanisms of the few events that occurred within this gap did not require significant overpressures. This gap suggests that the two fault segments may be linked by a structural bend. Given the fault segment location and the right-lateral sense of slip of the faults, this bend would correspond to a releasing bend (Figure 11). The presence of a releasing bend linking the two fault segments agrees with the structural regime (normal and strike-slip regimes) of our set of focal mechanisms. This interpretation is also consistent with Sanchez et al. [2010, 2011], who suggested that the Ubaye area is a transtensional domain characterized by a pull-apart-like opening.

[48] Finally, the vertical NW-SE slice of Figure 11 displays individual patches of fluid overpressure along the Ubaye fault zone. A central area of low overpressure is bordered by two high overpressure patches, one to the north and one to the south of cluster CL1. This spatial pattern probably reflects physical heterogeneities enabling fluid pressure buildup. The heterogeneities could be linked with local variations of hydraulic properties such as porosity or permeability, or with local variations of rock mechanics properties such as friction, Young modulus, or Poisson ratio.

\section{Discussion}

[49] The 2003-2004 Ubaye swarm shows a clear migration of hypocenters from north to south along cluster CL1 [Jenatton et al., 2007]. This hypocenter migration has been previously interpreted as resulting from a fluid diffusion mechanism along the Ubaye fault zone [Jenatton et al., 2007; Daniel et al., 2011]. Such diffusion is often viewed as the footprint of a high-pressure fluid upwelling process from depth, through a high-permeability channel (e.g., fault intersection and releasing bend), enabling diffusion along a fault zone [Miller et al., 2004; Cappa et al., 2009; Yukutake et al., 2011]. Upwelling of high-pressure fluids can itself be explained by a fault-valve mechanism [Sibson, 1990]. According to this model, fluids of magmatic or mantellic origin are released at depth but cannot escape upward to the surface due to the presence of hydraulic barriers. Fluids are blocked below such barriers, and pore pressure progressively increases. With increasing fluid overpressure, the barrier eventually breaks and allows fluids to escape and to diffuse along the fault zone. Fluid diffusion then induces a progressive fluid overpressure decrease, both spatially and temporally [Miller et al., 2004].

[50] In the Argentera massif, the upwelling of fluids from depth is evidenced by several geothermal water springs. According to Baietto et al. [2009], the geothermal waters have a meteoric origin and present chemical compositions in equilibrium with physical conditions at a $5 \mathrm{~km}$ depth, close to the mean hypocentral depth of the Ubaye swarm. Leclère et al. [2012] proposed that geothermal waters could be a likely candidate for the triggering of the Ubaye swarm. However, their meteoric origin indicates that the pressurization of fluid at depth cannot be explained by the upwelling and accumulation of deep fluid origin below a hydraulic barrier. Indeed, the trapping of meteoric water into the fault zones appears to be more conceivable.

[51] Moreover, the releasing and diffusion of fluid overpressure through a fault zone, as it is implied by a model of upwelling, deep overpressured fluids, tend to disagree with the results presented in section 4 . Our results tend to dismiss the fluid diffusion model proposed in earlier studies [Jenatton et al., 2007; Daniel et al., 2011] for the following reasons. First, the spatial pattern of overpressure is discontinuous and presents a gap in a possible releasing bend (Figure 11). Second, fluid overpressure does not progressively decrease from the northwestern to the southeastern part of cluster CL1, as it would be expected with a fluid diffusion model. Conversely, it increases and reaches its maximum values in the southeastern part of cluster CL1. These considerations dismiss both an upwelling of deep overpressured fluids for the Ubaye swarm and a migration of microseismic events related to fluid diffusion processes.

[52] Another process enabling the development of fluid overpressure within a fault zone is fault compaction [Blanpied et al., 1992; Byerlee, 1993]. This mechanism requires compaction of the saturated fault gouge and sealing of the fault zone to prevent water escape. Under these conditions, the pressurization of water in the fault zone lowers the effective normal stress and thus favors fault reactivation. In the Ubaye case, the saturation of fault zones may come from the geothermal water fluid flow [Baietto et al., 2009]. Fault sealing can occur by a pressure-solution mechanism [Renard et al., 2000; Gratier et al., 2003]. Indeed, pressure solution is efficient in quartz-rich rocks, commonly observed along fault exposures in the Argentera massif [Baietto et al., 2009; Leclère et al., 2012]. Pressure solution reduces porosity and permeability by healing cracks and pores. Reduction of porosity and permeability prevents the water from escaping and enables fluid pressure buildup.

[53] In the following, we propose a new model for the generation of the 2003-2004 Ubaye seismic swarm. The model for this swarm must reconcile the following observations: (1) seismic events migrated southeastward along cluster CL1, (2) moderate fluid overpressure accompanied the swarm inception and was followed by the development of large fluid overpressure associated with the burst of seismic activity, (3) fluid overpressure developed in two distinct areas that were separated by an area of low/null overpressure, and (4) every distinct patch of fluid overpressure lasted for about 1 year.

[54] Stress transfer has already been mentioned as a possible mechanism favoring the migration of seismicity [Stein, 1999; Toda et al., 2002; Aoyama et al., 2002; Yukutake et al., 2011]. This hypothesis was tested in this study. By using the 3DDEF software [Gomberg and Ellis, 1993], we computed for every event of the 55-earthquake population analyzed above (section 4.4) the (cumulative) static Coulomb stress induced by all preceding events on the target fault plane associated with the focal mechanism of the event. Our results show that the magnitude of the Coulomb stress 
just before these events is always lower than $0.03 \mathrm{MPa}$ and often has negative values. From these simulations, we conclude that the triggering of seismicity by static Coulomb stress transfer is not significant and cannot explain the migration observed during the 2003-2004 Ubaye swarm.

[55] Aseismic slip could be another viable mechanism favoring the migration of seismicity [Schmidt et al., 2005; Lohman and McGuire, 2007; Chen and Shearer, 2011]. For example, at Salton Sea, California, Lohman and McGuire [2007] proposed that the migration of seismic events could be explained by aseismic slip at depth. Their interpretation was based on evidence obtained using geodetic data. Event migration velocities for Salton Trough swarms $(0.1-1 \mathrm{~km} / \mathrm{h})$ is usually larger than the migration velocities for the Ubaye $\operatorname{swarm}\left(\sim 5.10^{-4} \mathrm{~km} / \mathrm{h}\right)$. This difference in migration velocities can be related to the difference in strain rate between the high strain rate of the creeping segment of the San Andreas Fault ( $\sim 20 \mathrm{~mm} / \mathrm{yr}$; [Titus et al., 2006]) and the low strain rate of the Southwestern Alps $(\sim 1 \mathrm{~mm} / \mathrm{yr}$; [Calais et al., 2002; Delacou et al., 2008]).

[56] The cumulated seismic moment of the Ubaye swarm corresponds to a $M_{L} 4$ equivalent single event, which would have occurred on a $\sim 5 \mathrm{~km}^{2}$ fault surface. Besides, the rupture surface area of the 2003-2004 Ubaye swarm, as suggested by the spatial distribution of hypocenters, is larger than $5 \mathrm{~km}^{2}$ and rather corresponds to a potential magnitude of $M_{L} 5.5$ to 6 . This discrepancy could reflect the signature of a driving mechanism that involves aseismic processes. No geodetic data, which could help testing this hypothesis, are available in the study area for 2003 or 2004 . Note that the occurrence of aseismic slip during the Ubaye swarm can explain the observed migration of epicenters from the northern part to the southern part of CL1 (Figure 2) as it was demonstrated at Salton Trough in California by Lohman and McGuire [2007] and Chen and Shearer [2011].

[57] The possibility of aseismic slip may provide information about the slip behavior of the fault. Indeed, rate-and-state friction laws discriminate two categories of fault behaviors, based on friction coefficient changes at increasing sliding velocities. Velocity-strengthening faults exhibit stable sliding, or aseismic slip, with increasing sliding velocities, whereas velocity-weakening faults exhibit potentially unstable sliding, or coseismic sliding, with increasing sliding velocities [Dieterich, 1978; Ruina, 1983; Scholz, 1998]. The slip behavior is governed by the friction properties of the constitutive material (e.g., gouge and breccia) or by the thickness of the gouge layer [Marone et al., 1990; Marone and Saffer, 2007]. In the Ubaye case, aseismic slip suggests that faults are characterized by a velocity-strengthening behavior inhibiting the triggering of moderate to large earthquakes and conversely favoring aseismic slip and microearthquakes.

[58] During the 2003-2004 Ubaye swarm, fault compaction and aseismic slip could have acted in concert, with compaction causing the development of the fluid overpressure and aseismic slip affecting the migration of events. Moreover, the similarity between fluid overpressure and spatial migration of events suggests that these two mechanisms were probably related. The mutual dependence of these two processes can be explained by aseismic slip-induced fault compaction, also known as "creep compaction" [see Sleep and Blanpied, 1994; Gratier et al., 2003; Fitzenz et al., 2007]. During creep compaction, aseismic slip compacts and seals fault zones, thus contributing to an increase in pore fluid pressure. In the overpressurized volumes, the fluid overpressure in turn enables the reactivation of faults misoriented with respect to the stress field (i.e., faults requiring fluid overpressures to be reactivated). Fault reactivation may break the hydraulic barrier during motion and may induce a fault-valve behavior [Sibson, 1990], pressurizing the volume surrounding the fault and favoring the reactivation of adjacent faults. The low energy released during fault slip motions, deduced from the low-magnitude events, induced a low degree of fracturing and dilatancy around the fault. Consequently, the low permeability and dilatancy of the fault zone prevent significant fluid pressure decrease and may explain the sustained patch of overpressure ( 1 year long) to the NW and SE of cluster CL1.

[59] Also, our fault model is consistent with the gap in overpressure observed in the middle part of the CL1 cluster (Figures 10 and 11). If this gap marks the emplacement of a releasing bend, the deformation expected in this area is characterized by dilatation, with associated porosity increase. Development of porosity would thus inhibit the development of fluid overpressure, explaining the lack of such overpressure in our observations.

[60] During the swarm activity, the temporal variations of the seismic moment presented on Figure 9c could be explained by volume changes as suggested by McGarr [1976]. McGarr [1976] showed good correlations between volume changes during fluid injection into wells or during rock mining and the seismic moments of the triggered earthquakes. In the case of the Ubaye swarm, the variations of the seismic moments through time could be explained by volume changes induced by creep compaction (decrease of the fault zone volume). Given that creep compaction is the mechanism allowing fluid pressure buildup, the correlation between fluid overpressures and seismic moments can be explained by volume decreases induced by fault zone compaction. The correlation between fluid overpressures and seismic moments strengthens our interpretation that creep compaction is a mechanism active during the 2003-2004 Ubaye swarm.

[61] At swarm inception, the development of moderate fluid overpressure (35 MPa) enables the reactivation of normal, transtensional, and strike-slip faults. During the seismic burst activity, the development of larger fluid overpressures (up to $55 \mathrm{MPa}$ ) progressively enables the reactivation of further misoriented normal, transtensional, and transpressional faults. This change in the faulting regime during the seismic burst activity is also accompanied by a change of the b-value [Jenatton et al., 2007] with a mean b-value close to 1.2 before the seismic burst and a mean b-value close to 1.4 after the seismic burst. The correlation between the b-value and the faulting regime was demonstrated by Schorlemmer et al. [2005], who found that normal faulting events have the highest $b$ values, thrust events have the lowest values, and strike-slip events have intermediate values. However, the faulting regime is controlled by the orientation and components of the principal stress axes (see Bott's [1959] hypothesis), which are themselves sensitive to the value of fluid pressure (following Terzaghi's equation of effective stress). Consequently, the variations of the $b$ values for the Ubaye swarm may correspond to variations of the magnitudes of the principal stress axes caused by fluid overpressures through time. 


\section{Conclusion}

[62] In this study, we document spatiotemporal changes in fluid overpressures during the 2003-2004 Ubaye seismic swarm. The computation of these changes is based on a Mohr-Coulomb analysis carried out on a selection of 51 significant focal mechanisms. The analysis enables to characterize a strong spatial heterogeneity in overpressure distribution within the swarm hypocentral area and to refine the preliminary estimates reported by Leclère et al. [2012]. We show the following:

[63] 1. The Ubaye swarm activity was controlled by fluid overpressurization, with overpressures $\partial P f$ close to $35 \mathrm{MPa}$ at swarm inception, increasing up to $55 \mathrm{MPa}$ during the burst of seismic activity, and finally dissipating toward the end of the crisis.

[64] 2. Overpressure developed in patches localized along two parallel NW-SE faults segments, on both sides of a releasing bend structure.

[65] We propose the following:

[66] 1. The migration of earthquake hypocenters could have been induced by aseismic slip.

[67] 2. Aseismic slip episodes induced creep compaction of fault zones, which in turn enabled fluid overpressures to develop. This is supported by the evidence that the migration of events and the development of fluid overpressures in the Ubaye area are strongly dependent and are probably governed by aseismic processes.

[68] Based on previous results [Jenatton et al., 2007; Daniel et al., 2011; Leclère et al., 2012] and those obtained in this study, a scenario reconciling structural, hydrogeological, and mechanical observations can be proposed for the 2003-2004 Ubaye swarm. In this scenario, meteoric waters infiltrate through the Argentera massif at depth and saturate the fault zones. Meteoric waters are then trapped in the fault zones because of hydrothermal sealing of the damage zones and because of a low-permeability sedimentary lid preventing the water to escape. Aseismic slip could then drive the seismic migration toward the SE along cluster CL1 and could induce creep compaction. The simultaneous occurrence of creep compaction and hydrothermal sealing processes, and the presence of the low-permeability lid enabled the development of fluid overpressure patches in two distinct areas: NW and SE of cluster CL1. These two distinct areas appear to be located along two overlapping parallel fault segments defining a pull-apart-like, releasing bend structure. This proposed structure is characterized by low to null overpressure, i.e., high porosity or high permeability. Conversely, the sustainment of overpressure patches for about 1 year argues in favor of low-permeability fault zones.

[69] Future studies of the Ubaye swarm driving processes should take into account the dynamic response of the fault system to compaction and pressure buildup phenomena. As nonlinear transient dynamic deformation processes may present strong short-lived variations, they could have a significant impact on earthquake triggering and need to be studied thoroughly.

[70] Acknowledgments. Funding of this study by the INSU Catastrophes Telluriques program is gratefully acknowledged. We thank the team in charge of the maintenance of the Sismalp seismological network, for having provided us data relative to the 2003-2004 Ubaye seismic swarm. We thank two anonymous reviewers for constructive comments and $\mathrm{E}$. Mariani for English improvement.

\section{References}

Amitrano, D., and J. Schmittbuhl (2002), Fracture roughness and gouge distribution of a granite shear band, J. Geophys. Res., 107(B12), 2375, doi:10.1029/2002JB001761.

Amontons, G. (1699), De la résistance causée dans les machines, tant par le frottement des parties qui les composent que par la roideur des corps qu'on y employe, et la manière de calculer l'un et l'autre, Mémoire de l'Académie Royale, 206-227.

Aoyama, H., M. Takeo and S. Ide (2002), Evolution mechanisms of an earthquake swarm under the Hida Mountains, central Japan, in 1998, J. Geophys. Res., 107(B8), doi:10.1029/2001JB000540.

Baietto, A., P. Perello, P. Cadoppi, and G. Martinotti (2009), Alpine tectonic evolution and thermal water circulations of the Argentera massif (SouthWestern Alps), Swiss J. Geosci., 102, 223-245.

Bakun, W. H. (1984), Seismic moments, local magnitudes, and coda-duration magnitudes for earthquakes in central California, Bull. Seismol.Soc. Am., 74, 439-458.

Bella, F., P. F. Biagi, M. Caputo, E. Cozzi, G. Della Monica, A. Ermini, W. Plastino, and V. Sgrigna (1998), Aquifer-induced seismicity in the Central Apennines (Italy), Pure Appl. Geophys., 153, 179-194.

Béthoux, N., M. Cattaneo, P. Y. Delpech, C. Eva, and J. P. Réhault (1988), Mécanismes au foyer de séismes en mer ligure et dans le sud des Alpes occidentales : Résultats et interprétations, C. R. Acad. Sci., Sér. II, 317, 71-77.

Blanpied, L. B., D. A. Lockner, and J. D. Byerlee (1992), An earthquake mechanism based on rapid sealing of faults, Nature, 358, 574-576.

Bogdanoff, S. (1986), Evolution de la partie occidentale du massif cristallin externe de l'Argentera. Place dans l'arc Alpin, Géol. France, 4, 433-453.

Bollinger, L., F. Perrier, J. P. Avouac, S. Sapkota, U. Gautam, and D. R. Tiwari (2007) Seasonal modulation of seismicity in the Himalaya of Nepal, Geophys. Res. Lett., 34, L08304, doi:10.1029/2006GL029192.

Bott, M. H. P. (1959), The mechanics of oblique slip faulting, Geol. Mag., 96, 109-117.

Bouchon, M., H. Karabulut, M. Aktar, S. Özalaybey, J. Schmittbuhl, and M. P. Bouin (2011), Extended Nucleation of the 1999 Mw 7.6 Izmit Earthquake, Science, 331, 877-880.

Bräuer, K., H. Kämpf, and G. Strauch (2009), Earthquake swarms in nonvolcanic regions: What fluids have to say, Geophys. Res. Lett., 36, L17309, doi:10.1029/2009GL039615.

Brudy, M., M. D. Zoback, K. Fuchs, F. Rummel, and J. Baumgärtner (1997), Estimation of the complete stress tensor to $8 \mathrm{~km}$ depth in the KTB scientific drill holes: Implications for crustal strength, J. Geophys. Res., 102(B8), 18,453-18,475, doi:10.1029/96JB02942.

Byerlee, J. (1993), Model for episodic flow of high-pressure water in fault zones before earthquakes, Geology, 21, 303-306.

Calais, E., J. M. Nocquet, F. Jouanne, and M. Tardy (2002), Current strain regime in the Western Alps from continuous Global Positioning System measurements, 1996-2001, Geology, 30, 651-654.

Cappa, F., J. Rutqvist and K. Yamamoto (2009), Modeling crustal deformation and rupture processes related to upwelling of deep CO2-rich fluids during the 1965-1967 Matsushiro earthquake swarm in Japan, J. Geophys. Res., 114, B10304, doi:10.1029/2009JB006398.

Chen, X., and P. M. Shearer (2011), Comprehensive analysis of earthquake source spectra and swarms in the Salton Trough, California, J. Geophys. Res., 116, B09309, doi:10.1029/2011JB008263.

Cornet, F. H., and D. Burlet (1992), Stress field determinations in France by hydraulic tests in boreholes, J. Geophys. Res., 97(B8), 11,829-11,849, doi:10.1029/90JB02638.

Cornet, F. H., Y. Wileveau, B. Bert, and J. Darcy (1997), Complete stress determination with the HTPF tool in mountainous region, Int J. Rock Mech. Min Sci, 34, 3-4.

Costain, J. K., G. A. Bollinger, and J. A. Speer (1987), Hydroseismicity-A hypothesis for the role of water in the generation of intraplate seismicity, Geology, 15, 618-621.

Cox, S. F. (2010), The application of failure mode diagrams for exploring the roles of fluid pressure and stress states in controlling styles of fracture controlled permeability enhancement in faults and shear zones, Geofluids, 10, 217-233.

Daniel, G., et al. (2011). Changes in effective stress during the 2003-2004 Ubaye seismic swarm, France. J. Geophys. Res., 116, B01309, doi:10.1029/2010JB007551.

Delacou, B., C. Sue, J. D. Champagnac, and M. Burkhard (2004), Presentday geodynamics in the bend of the Western and Central Alps as constrained by earthquake analysis, Geophys. J. Int., 158, 753-774.

Delacou, B., C. Sue, J. M. Nocquet, J. D. Champagnac, E. Calais, and C. Allanic (2008), Quantification of western alpine geodetic strain. Comparisons with seismotectonics, Swiss J. Geosci., 101, 377-385, doi:10.1007/s00015-008-1271-3.

Dieterich, J. (1978), Time-dependent friction and the mechanics of stick-slip, Pure Appl. Geophys., 116, 790-806. 


\section{LECLÈRE ET AL.: FLUID PRESSURE DURING THE UBAYE SWARM}

Dieterich, J. (1994), A constitutive law for rate of earthquake production and its application to earthquake clustering, J. Geophys. Res., 99(B2), 2601-2618, doi:10.1029/93JB02581.

Dieterich, J., V. Cayol, and P. Okubo (2000), The use of earthquake rate changes as a stress meter at Kilauea Volcano, Nature, 408, 457-460.

Evans, K. F. (2005), Permeability creation and damage due to massive fluid injections into granite at $3.5 \mathrm{~km}$ at Soultz: 2. Critical stress and fracture strength, J. Geophys. Res., 110, B04204, doi:10.1029/2004JB003169.

Faure-Muret, A. (1955), Etudes géologiques sur le Massif de l'ArgenteraMercantour et ses enveloppes sédimentaires. Mémoires pour servir à l'explication de la carte géologique détaillée de la France, Imprimerie Nationale, Paris, 336 pp.

Fitzenz, D. D., A. Jalobeanu, and S. H. Hickman (2007), Integrating laboratory creep compaction data with numerical fault models: A Bayesian framework, J. Geophys. Res., 112, B08410, doi:10.1029/2006JB004792.

Fréchet, J., and N. Pavoni (1979), Etude de la sismicité de la zone Briançonnaise entre Pelvoux et Argentera (Alpes Orientales) à l'aide d'un réseau de stations portables, Eclogae Geologicae Helvetica, 72, 763-779.

Fry, N. (1989), Southwestward thrusting and tectonics of the Western Alps, Geol. Soc. Lond. Spec. Publ, 45, 83-109, doi:10.1144/GSL.SP.1989.045.01.05.

Gomberg, J., and M. Ellis (1993), 3D-DEF: A user's manual, U.S. Geol. Surv. Open File Rep, 93-547.

Got, J. L., V. Monteiller, J. Guilbert, D. Marsan, Y. Cansi, C. Maillard, and J. P. Santoire (2011), Strain localization and fluid migration from earthquake relocation and seismicity analysis in the western Vosges (France), Geophys. J. Int., 185, 365-384, doi:10.1111/j.1365-246X.2011.04944.x.

Gratier, J. P., P. Favreau, and F. Renard (2003), Modeling fluid transfer along California faults when integrating pressure solution crack sealing and compaction processes, J. Geophys. Res., 108(B2), 2104, doi:10.1029/ 2001JB000380.

Guyoton, F., J. Fréchet, and F. Thouvenot (1990), La crise sismique de Janvier 1989 en Haute-Ubaye (Alpes-de-Haute-Provence, France): étude fine de la sismicité par le nouveau réseau SISMALP, C. R. Acad. Sci. Sér. II, 311, 985-991.

Hainzl, S. and Y. Ogata (2005), Detecting fluid signals in seismicity data through statistical earthquake modeling, J. Geophys. Res., 110, B05S07, doi:10.1029/2004JB003247.

Hainzl, S., T. Kraft, J. Wassermann, H. Igel, and E. Schmedes (2006) Evidence for rainfall-triggered earthquake activity, Geophys. Res. Lett. 33, L19303, doi:10.1029/2006GL027642.

Hainzl, S., T. Fischer, and T. Dahm (2012), Seismicity-based estimation of the driving fluid pressure in the case of swarm activity in Western Bohemia, Geophys. J. Int., 191, 271-281, doi:10.1111/j.1365-246X.2012.05610.x.

Hancock, P. L. (1985), Brittle microtectonics: Principles and practice, J. Struct. Geol., 7, 437-457.

Hensch, M., C. Riedel, J. Reinhardt, and T. Dahm (2008), Hypocenter migration of fluid-induced earthquake swarms in the Tjörnes Fracture Zone (North Iceland), Tectonophysics, 447, 80-94.

Hickman, S., R. Sibson, and R. Bruhn (1995), Introduction to special section: Mechanical involvement of fluids in faulting, J. Geophys. Res., $100,12,831-12,840$

Hill, D. P. (1977), A model for earthquake swarm, J. Geophys. Res., 82, 1347-1352, doi:10.1029/JB082i008p01347.

Jaeger, J. C., N. G. W. Cook, and R. W. Zimmerman (2007), Fundamentals of Rock Mechanics, 4th ed, pp. 475, Blackwell, Malden, Mass.

Jenatton, L., R. Guiguet, F. Thouvenot, and N. Daix (2007), The 16,000-event 2003-2004 earthquake swarm in Ubaye (French Alps), J. Geophys. Res., 112, B11304, doi:10.1029/2006JB004878

Kerckhove, C. (1969), La zone du flysch dans les nappes de l'EmbrunaisUbaye (Alpes Occidentales), Géologie Alpine, 45, 1-202.

Kerckhove, C., et al. (1980), Feuille de Gap, Carte Géol. France. Map 35, scale 1:250,000. Bureau de Recherches Géologiques et Minières, Orléans, France.

Kurz, J. H., T. Jahr, and G. Jentzsch (2004), Earthquake swarm examples and a look at the generation mechanism of the Vogtland/Western Bohemia earthquake swarms, Phys. Earth Planet. Inter., 142, 75-88.

Labaume, P., J. F. Ritz, and H. Philip (1989), Failles normales récentes dans les Alpes sud-occidentales: Leurs relations avec la tectonique compressive, C. R. Acad. Sci. Sér. II, 308, 1553-1560.

Larroque, C., B. Delouis, B. Godel, and J. M. Nocquet (2009), Active deformation at the Southwestern Alps-Ligurian basin junction (France-Italy boundary): Evidence for recent change from compression to extension in the Argentera massif, Tectonophysics, 467, 22-34.

Leclère, H., O. Fabbri, G. Daniel, and F. Cappa (2012), Reactivation of a strikeslip fault by fluid overpressuring in the southwestern French-Italian Alps, Geophys. J. Int., 189, 29-37, doi:10.1111/j.1365-246X.2011.05345.x.

Lohman, R. B., and J. J. McGuire (2007), Earthquake swarms driven by aseismic creep in the Salton Trough, California, J. Geophys. Res., 112, B04405, doi:10.1029/2006JB004596.

Marone, C., and D. M. Saffer (2007), Fault friction and the upper transition from seismic to aseismic faulting, in The Seismogenic Zone of Subduction
Thrust Faults, edited by T. Dixon and J. Moore, Colombia University Press, New York, pp. 346-369.

Marone, C., C. B. Raleigh, and C. H. Scholz (1990), Frictional Behavior and Constitutive Modeling of Simulated Fault Gouge, J. Geophys. Res., 95 7007-7025, doi:10.1029/JB095iB05p07007.

McGarr, A. (1976), Seismic moments and volume changes, J. Geophys Res., 81(8), 1487-1494, doi:10.1029/JB081i008p01487.

Ménard, G.. (1988), Structures and kinematics of collisional orogen: The Western and Central Alps, $\mathrm{PhD}$ thesis, University of Grenoble, France, $278 \mathrm{pp}$ Michael, A. J. (1987), Use of focal mechanisms to determine stress: A control study, J. Geophys. Res., 92, 357-368, doi:10.1029 JB092iB01p00357.

Miller, S. A., C. Collettini, L. Chiaraluce, M. Cocco, M. R. Barchi, and B. Kaus (2004), Aftershocks driven by a high pressure CO2 source at depth, Nature, 427, 724-727.

Nicolas, M., N. Béthoux, and B. Madeddu (1998), Instrumental seismicity of the WesternAlps: A revised catalogue, Pure Appl. Geophys., 152, 707-731.

Nur, A. (1974), Matsushiro, Japan, earthquake swarm: Confirmation of the dilatancy-fluid diffusion model, Geology, 2, 217-221.

Nur, A., and J. R. Booker (1972), Aftershocks caused by pore fluid flow?, Science, 175, 885-887, doi:10.1126/science.175.4024.885.

Reasenberg, P. A. and D. Oppenheimer (1985), FPFIT, FPPLOT, and FPPAGE: Fortran computer programs for calculating and displaying earthquake fault-plane solutions, U.S. Geological Survey Open-File Report, 85-739.

Renard, F., E. Brosse, and J. P. Gratier (2000), The different processes involved in the mechanism of pressure solution in quartz-rich rocks and their Interactions, in Quartz Cementation in Sandstones, edited by R. H. Worden and S. Morad, Blackwell Publishing Ltd., Oxford, UK, doi:10.1002/9781444304237.ch5.

Rigo, A., N. Béthoux, F. Masson, and J. F. Ritz (2008), Seismicity rate and wave-velocity variations as consequences of rainfall: The case of the catastrophic storm of September 2002 in the Nîmes Fault region (Gard, France), Geophys. J. Int., 173, 473-482.

Ruina, A. L. (1983), Slip instability and and state-variable friction laws, J. Geophys. Res., 88, 359-370.

Sanchez, G., Y. Rolland, M. Corsini, R. Braucher, D. Bourlès, M. Arnold, and G. Aumaître (2010), Relationships between tectonics, slope instability and climate change: Cosmic ray exposure dating of active faults, landslides and glacial surfaces in the SW Alps, Geomorphology, 117, $1-13$

Sanchez, G., Y. Rolland, M. Jolivet, S. Brichau, M. Corsini, and A. Carter (2011), Exhumation controlled by transcurrent tectonics: The ArgenteraMercantour massif (SW Alps), Terra Nova, 23, 116-126, doi:10.1111/ j.1365-3121.2011.00991.x

Schmidt, D. A., R. Bürgmann, R. M. Nadeau, and M. d'Alessio (2005), Distribution of aseismic slip rate on the Hayward fault inferred from seismic and geodetic data, J. Geophys. Res., 110, B08406, doi:10.1029/ 2004JB003397.

Scholz, C. H. (1998), Earthquakes and friction laws, Nature, 39, 37-42.

Schorlemmer, D., S. Wiemer, and M. Wyss (2005), Variations in earthquake-size distribution across different stress regimes, Nature, 437, 539-542.

Secor, D. T. (1965), Role of fluid pressure in jointing, Am. J. Sci., 263, 633-646.

Shapiro, S. A., E. Huenges, and G. Borm (1997), Estimating the crust permeability from fluid-injection-induced seismic emission at the KTB site, Geophys. J. Int., 131, F15-F18, doi:10.1111/j.1365-246X.1997. tb01215.x.

Sibson, R. H. (1985), A note on fault reactivation, J. Struct. Geol., 7, 75-754.

Sibson, R. H. (1990), Rupture nucleation on unfavorably oriented faults, Bull. Seismol. Soc. Am., 80, 1580-1604.

Sibson, R. H. (2000), A brittle failure mode plot defining conditions for highflux flow, Econ. Geol., 95, 41-48.

Sleep, N. H., and M. L. Blanpied (1994), Ductile creep and compaction: A mechanism for transiently increasing fluid pressure in mostly sealed faul zones, Pure Appl. Geophys., 143, 9-40.

Stein, R. S. (1999), The role of stress transfer in earthquake occurrence, Nature, 402, 605-609, doi:10.1038/45144.

Sue, C., and P. Tricart (2003), Neogene to ongoing normal faulting in the inner Western Alps: A major evolution of the late Alpine tectonics, Tectonics, 22(5), 1050, doi:10.1029/2002TC001426.

Sue, C., F. Thouvenot, J. Fréchet, and P. Tricart (1999), Widespread extension in the core of the western Alps revealed by earthquake analysis, J. Geophys. Res., 104(B11), 25,611-25,622, doi:10.1029/1999JB900249.

Terakawa, T., A. Zoporowski, B. Galvan, and S. Miller (2010), Highpressure fluid at hypocentral depths in the L'Aquila region inferred from earthquake focal mechanisms, Geology, 38, 995-998.

Thouvenot, F., and J. Fréchet (2006), Seismicity along the northwestern edge of the Adria microplate, in The Adria Microplate: GPS Geodesy, 


\section{LECLÈRE ET AL.: FLUID PRESSURE DURING THE UBAYE SWARM}

Tectonics, and Hazards, edited by N. Pinter et al., pp. 335-349, Springer, Dordrecht, Netherlands, doi:10.1007/1-4020-4235-3 23.

Titus, S. J., C. DeMets, and B. Tikoff(2006), Thirty-five-year creep rates for the creeping segment of the San Andreas fault and the effects of the 2004 Parkfield earthquake: Constraints from alignment arrays, continuous global positioning system, and creepmeters, Seismol. Soc. Am. Bull., 96, 250-268, doi:10.1785/0120050811.

Toda, S., R. Stein, and T. Sagiya (2002), Evidence from the AD 2000 Izu islands earthquake swarm that stressing rate governs seismicity, Nature, 419, 58-61.

Vidale, J. E., K. L. Boyle, and P. M. Shearer (2006), Crustal earthquake bursts in California and Japan: Their patterns and relation to volcanoes, J. Geophys. Res., 33, L20313, doi:10.1029/2006GL027723.
Weise, S. M., K. Bräuer, H. Kämpf, G. Strauch, and U. Koch (2001), Transport of mantle volatiles through the crust traced by seismically released fluids: A natural experiment in the earthquake swarm area Vogtland/NW Bohemia, Central Europe, Tectonophysics, 336, 137-150. Yukutake, Y., H. Ito, R. Honda, M. Harada, T. Tanada, and A. Yoshida (2011), Fluid-induced swarm earthquake sequence revealed by precisely determined hypocenters and focal mechanisms in the 2009 activity at Hakone volcano, Japan, J. Geophys. Res., 116, B04308, doi:10.1029/ 2010JB008036.

Zoback, M. D., and J. H. Healy (1992), In situ stress measurements to $3.5 \mathrm{~km}$ depth in the Cajon Pass Scientific Research Borehole: Implications for the mechanics of crustal faulting, J. Geophys. Res., 97(B4), 5039-5057, doi:10.1029/91JB02175. 